US Army Corps

of Engineers ${ }_{\circledast}$

Engineer Research and

Development Center

\title{
Environmental Life Cycle Assessment on CNTRENE® 1030 Material and CNT Based \\ Sensors
}

Mark Chappell, Wu-Sheng Shih, Cynthia Price, Rishi Patel, Daniel

Janzen, John Bledsoe, Kay Mangelson, Lesley Miller, Brooke

Stevens, Joshua LeMonte, Joseph Demster, Vijaya Kayastha,

Christopher Landorf, Stephen Gibbons, and Chris Cox 
The US Army Engineer Research and Development Center (ERDC) solves the nation's toughest engineering and environmental challenges. ERDC develops innovative solutions in civil and military engineering, geospatial sciences, water resources, and environmental sciences for the Army, the Department of Defense, civilian agencies, and our nation's public good. Find out more at www.erdc.usace.army.mil.

To search for other technical reports published by ERDC, visit the ERDC online library at https://erdclibrary.on.worldcat.org/discovery. 


\section{Environmental Life Cycle Assessment on CNTRENE ${ }^{\circledR} 1030$ Material and CNT Based Sensors}

Mark Chappell, Cynthia Price, Lesley Miller, Brooke Stevens, and Joshua LeMonte

Environmental Laboratory

US Army Engineer Research and Development Center

3909 Halls Ferry Road

Vicksburg, MS 39180-6199

Wu-Sheng Shih, Daniel Janzen, John Bledsoe, Kay Mangelson, Joseph Demster, Vijaya Kayastha, Christopher Landorf, Stephen Gibbons, and Chris Cox

Brewer Science

2401 Brewer Drive

Rolla, MO USA 65401

Rishi Patel

Jordan Valley Innovation Center, Missouri State University

524 N Boonville Ave

Springfield, MO 65806

Final report

Approved for public release; distribution is unlimited.

Prepared for U.S. Army Corps of Engineers

Washington, DC 20314-1000

Under Project A1090-FY19, "Rapid Carbon Nano-Technology” under PE 633728/479448/A1090 


\section{Abstract}

This report details a study investigating the environmental impacts associated with the development and manufacturing of carbon nanotube (CNT)based ink (called CNTRENE 1030 material) and novel CNT temperature, flex, and moisture sensors. Undertaken by a private-public partnership involving Brewer Science (Rolla, Missouri), Jordan Valley Innovation Center of Missouri State University (Springfield, Missouri), and the US Army Engineer Research and Development Center (Vicksburg, Mississippi), this work demonstrates the environmental life cycle assessment (ELCA) methodology as a diagnostic tool to pinpoint the particular processes and materials posing the greatest environmental impact associated with the manufacture of the CNTRENE material and CNT-based sensor devices. Additionally, ELCA tracked the degree to which optimizing the device manufacturing process for full production also changed its predicted marginal environmental impacts.

DISCLAIMER: The contents of this report are not to be used for advertising, publication, or promotional purposes. Citation of trade names does not constitute an official endorsement or approval of the use of such commercial products. All product names and trademarks cited are the property of their respective owners. The findings of this report are not to be construed as an official Department of the Army position unless so designated by other authorized documents. 


\section{Contents}

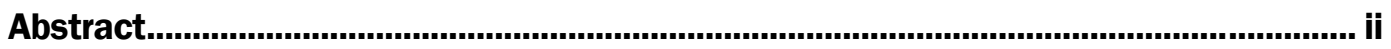

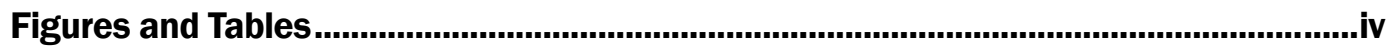

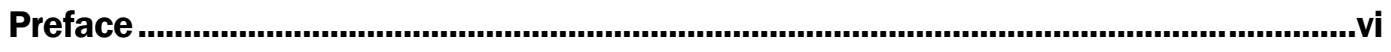

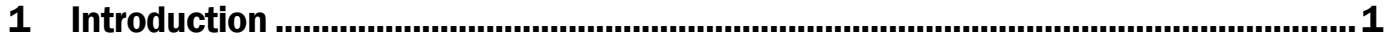

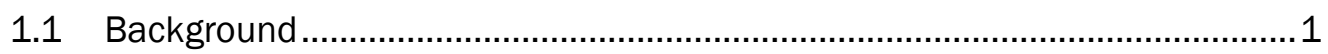

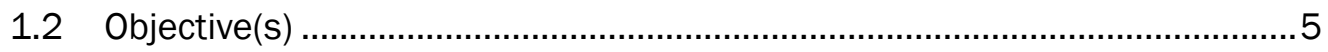

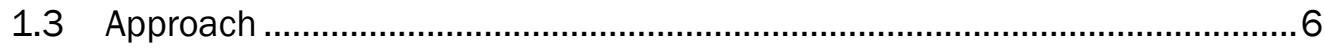

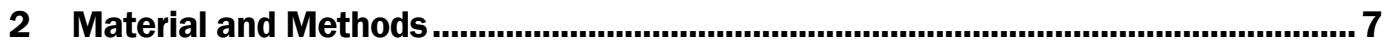

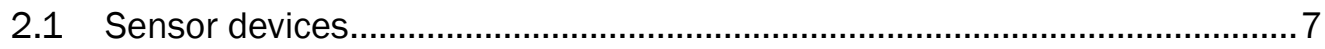

2.2 CNTRENE 1030 material and sensors ...................................................... 7

2.32 .3 Life cycle inventory and life cycle assessment....................................... 8

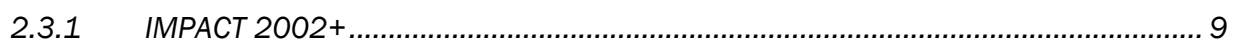

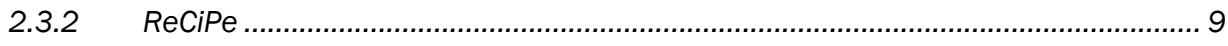

2.3.3 Eco-indicator 99................................................................................. 10

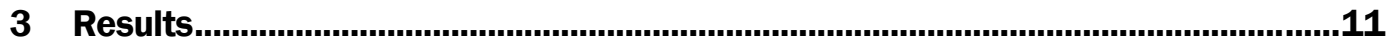

3.1 CNTRENE 1030 material.....................................................................11

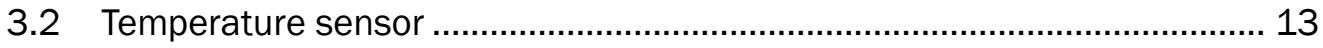

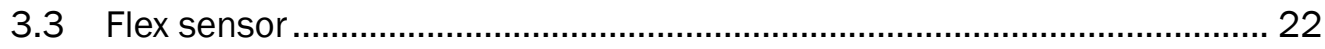

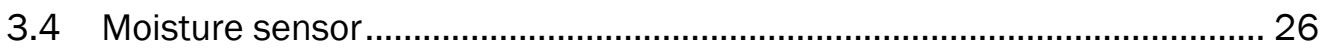

4 Discussion and Conclusions ................................................................................31

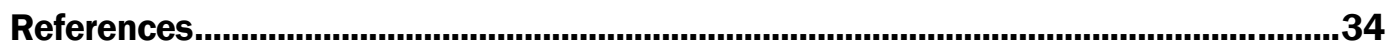

Report Documentation Page 


\section{Figures and Tables}

\section{Figures}

Figure 1. Schematic showing conceptual life cycle stages and potential emission sources of a theoretical product considered in the Environmental Life Cycle Assessment scenario.

Figure 2. Four main components of the ISO 14040,14044 defined ELCA methodology.

Figure 3. Generic structure of a fully printed sensor device with six layers: encapsulant materials; filters or other active materials; sensor material such as carbon nanotubes (CNTs) or graphene; printed conductors such as silver, gold, or copper; isolation or surface modification layers; and substrate such as PET, Kapton, or silicon.

Figure 4. Calculated environmental impacts for (A) original and (B) optimized CNTRENE 1030 material using the IMPACT2002+ model.

Figure 5. Pie chart representing the calculated process contributions to the environmental impacts for CNTRENE 1030 material.

Figure 6. Normalized impact scores for the temperature sensor, version 1, using IMPACT 2002+ model

Figure 7. Pie chart representing the calculated process contributions to the nonrenewable energy environmental impacts (IMPACT2002+) for the production of the CNTRENE 1030 material-based temperature sensor (version 1).

Figure 8. Pie chart representing the calculated process contributions to the global warming environmental impacts (IMPACT2002+) for the production of the

Figure 9. Pie chart representing the calculated process contributions to the respiratory inorganics environmental impacts (IMPACT2002+) for the production of the CNTRENE 1030 material-based temperature sensor (version 1).

Figure 10. Normalized impact scores for the temperature sensor, version 2, using IMPACT 2002+ model.

Figure 11. Normalized impact scores for the temperature sensor, version 3, using IMPACT 2002+ model

Figure 12. Pie chart representing the calculated process contributions to the respiratory inorganics environmental impacts (IMPACT2002+) for the production of the CNTRENE 1030 material-based temperature sensor (version 3).

Figure 13. Pie chart representing the calculated process contributions to the global warming environmental impacts (IMPACT2002+) for the production of the CNTRENE 1030 material-based temperature sensor (version 3).

Figure 14. Pie chart representing the calculated process contributions to the nonrenewable environmental impacts (IMPACT2002+) for the production of the CNTRENE 1030 material-based temperature sensor (version 3).

Figure 15. Normalized impact scores for the flex sensor, version 1, using IMPACT 2002+ model.

Figure 16. Normalized impact scores for the flex sensor, version 2, using IMPACT 
Figure 17. Normalized impact scores for the flex sensor, version 3, using IMPACT 2002+ model.

Figure 18. Pie chart representing the calculated process contributions to the global warming environmental impacts (IMPACT2002+) for the production of the carbonaceous nanomaterial-based flex sensor (version 3).

Figure 19. Normalized impact scores for the moisture sensor, version 1, using IMPACT 2002+ model.

Figure 20. Pie chart representing the calculated process contributions to the nonrenewable energy environmental impacts (IMPACT2002+) for the production of the CNTRENE 1030 material-based moisture sensor (version 1).

Figure 21. Normalized impact scores for the moisture sensor, version 2, using IMPACT 2002+ model.

Figure 22. Normalized impact scores for the moisture sensor, version 3, using IMPACT 2002+ model.

Figure 23. Change in the normalized total impact score with optimization of the temperature, moisture, and flex sensor manufacturing processes.

Figure 24. Change in the normalized total impact score with optimization of the temperature, moisture, and flex sensor manufacturing processes using (top)

Eco-indicator 99 and (bottom) ReCiPe. 33

\section{Tables}

Table 1. Midpoint and endpoint categories for the three life cycle impact assessment methods used in the case study. 


\section{Preface}

This study was conducted for the U.S. Army under PE633728 under the "Congressional Rapid Safe Advanced Materials" program, Project number 479448, Task number A1090. The technical monitor was Dr. Elizabeth Ferguson.

The work was performed by the Environmental Processes Branch of the Environmental Processes and Engineering Division, US Army Engineer Research and Development Center-Environmental Laboratory. At the time of publication, Mr. Warren Lorentz was Chief; and Dr. Elizabeth Ferguson was the Technical Director for Environmental Quality and Installations. The Deputy Director of ERDC-CERL was Dr. Brandon Lafferty, and the Director was Dr. Edmond Russo.

The Commander of ERDC was COL Teresa A. Schlosser and the Director was Dr. David W. Pittman.

Portions of this report have been modified and reprinted from M.A. Chappell, W-S Shih, J.K. Bledsoe, C. Cox, D. Janzen, S. Gibbons, R. Patel, A.J. Kennedy, J. Brame, M. Brondum, S.A. Diamond, J. Coleman, D. Edwards, J.A. Steevens. 2017. "Environmental Life Cycle Assessment for a Carbon Nanotube-Based Printed Electronic Sensor Platform.” Presented at TechConnect World Innovation Conference and Expo, Washington, DC, May 2017. https://techconnectworld.com/World2017/a.php?i=645. 


\section{Introduction}

\subsection{Background}

The industrial revolution occurred around the turn of the nineteenth century and brought about many changes throughout the world. The manufacturing and industrial processes developed then have continued to evolve, becoming more productive and efficient. In the late 1960s and early 1970 , manufacturers became concerned with the energy consumption and pollution prevention associated with manufacturing products. Eventually, researchers created a methodology called the environmental life cycle assessment (ELCA) to assess the potential environmental impacts associated with the development of a product (Klöpffer 1997; McManus and Taylor 2015; Rebitzer et al. 2004). The ELCA methodology includes all life-cycle stages of the product, from raw material acquisition and development prior to production, to the production or manufacturing stage and its associated processes, to the use stage fulfilling the intention of the product's development and manufacture, and eventually to the product's end of life involving disposal or recycling (Finnveden et al. 2009). This ELCA framework focuses only on the environmental impacts directly associated with the product's life cycle (called marginal impacts) without considering the overall state of the environment in general (Figure 1). In this way, ELCA fundamentally differs from risk assessment. 
Figure 1. Schematic showing conceptual life cycle stages and potential emission sources of a theoretical product considered in the Environmental Life Cycle Assessment scenario.

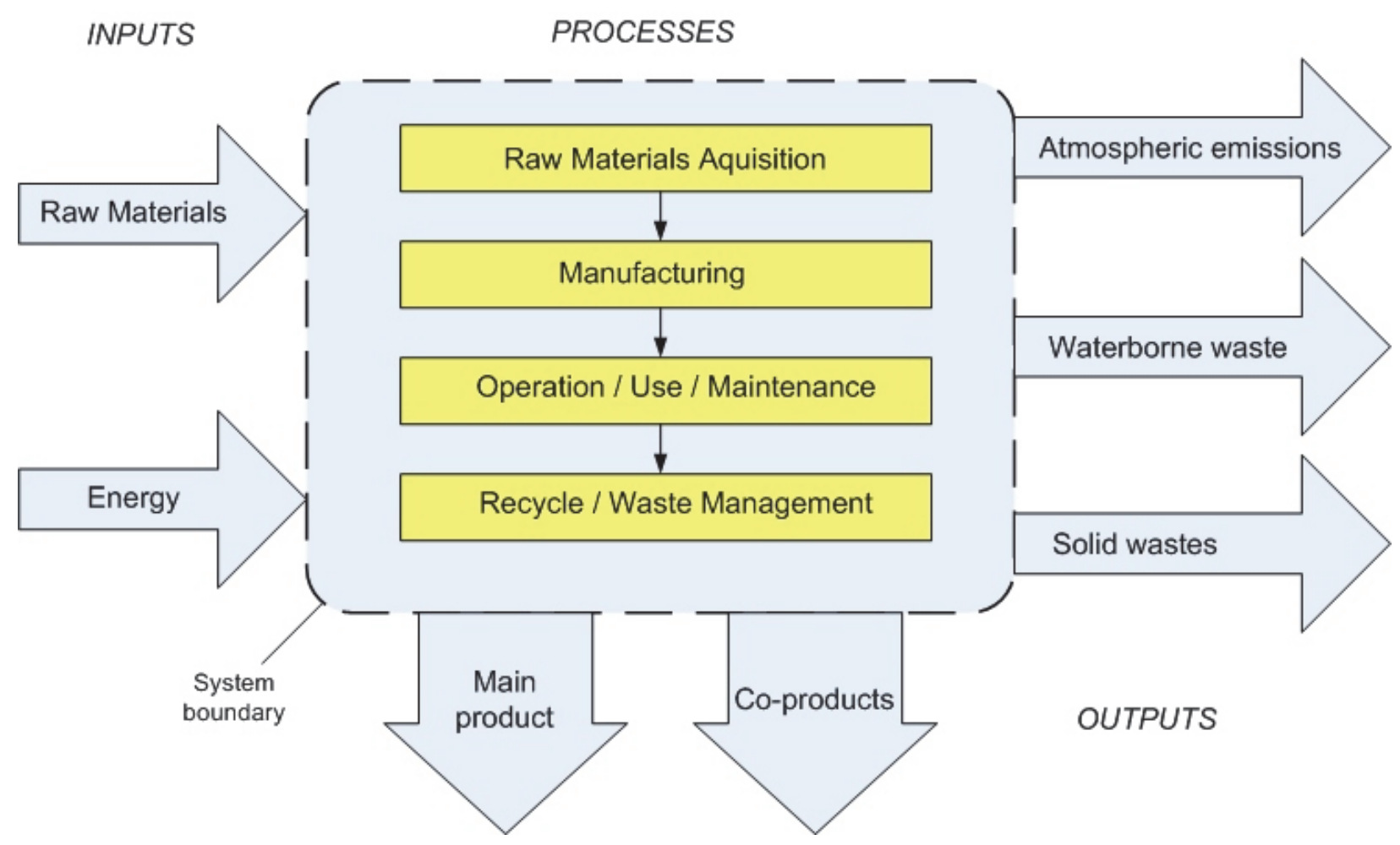

The ISO-defined ELCA methodology has four components (International Organization for Standarization 2006a, 20; 2006b, 46): (1) goal and scope, (2) inventory analysis, (3) impact assessment, and (4) interpretation (Figure 2). 
Figure 2. Four main components of the ISO 14040,14044 defined ELCA methodology.

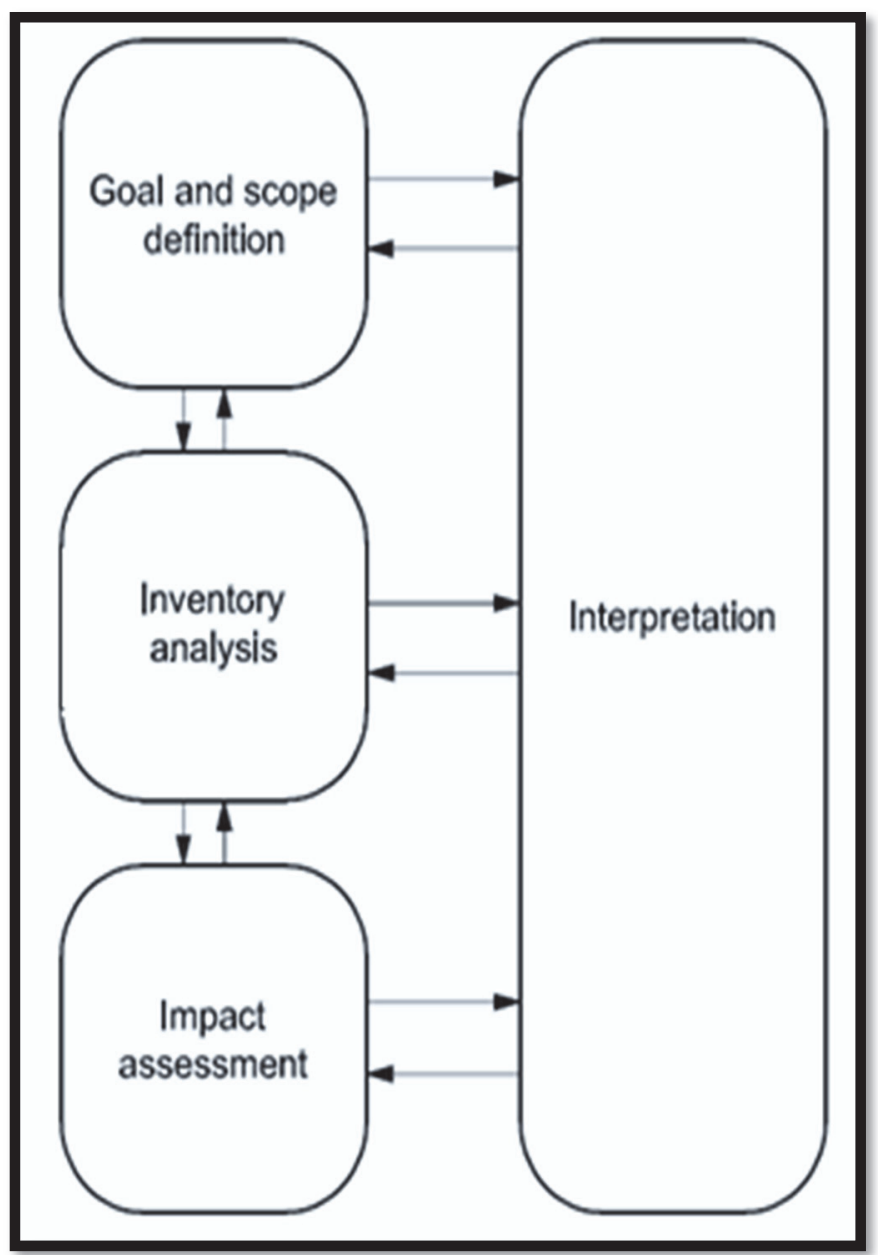

Within the foundation of the first component, which is the goal and overall purpose of the study, is the functional unit. The functional unit typically represents a rate at which a product may be manufactured, used, consumed over a period of time. Afterwards, the study scope is defined, representing the boundaries or extent of the product's life cycle to capture and important assumptions and sources to collect as well as information regarding the pertinent stakeholders in the ELCA study (Finnveden et al. 2009; Klöpffer 1997).

The second component, the inventory analysis, represents the step where a mathematical model including all of the technosphere inputs and associated activities associated represents that life-cycle stage. Technosphere inputs comprise all the structures of anthropogenic origin. This step includes determining the exact value or estimating the consumption of resources or raw materials, waste generated, and emissions produced over the life cycle 
of a product. The inventory analysis obtains the most complete picture possible of all life-cycle components of the product (Klöpffer 1997; Rebitzer et al. 2004). The more accurate the data, the fewer the assumptions applied, and, correspondingly, the less uncertainty in the ELCA output.

Next comes the impact assessment phase, representing the third component of ELCA, which uses the data obtained or estimated during the inventory analysis phase. The inventory is entered into different impact assessment models that include the details for the manufacturing processes, and the overall environmental impacts are modeled, which produces the final output (Rebitzer et al. 2004).

The interpretation step, representing the last component of ELCA, involves methods for understanding the calculations and determining their meaning and limitations. This step, shown in Figure 2, does not require a full study. For example, this work draws heavily from the first two steps in ELCA, using only computational values (as opposed to actual data) in the impact assessment step. Thus, the interpretation step provides diagnostic value to the inventory.

The impact assessment phase of ELCA has evolved over time into a multistep process within itself. The results from the impact assessment show the potential contributions to actual environmental impacts. The environmental impacts are grouped into endpoint categories that include natural resource use, human health, and ecological health (Pennington et al. 2004). The endpoint categories are then broken down into midpoint categories, which are specific effects such as global warming, carcinogens, noncarcinogens, ecotoxicity, mineral depletion (Jolliet et al. 2003). The impact assessment includes (1) classification, (2) characterization, (3) weighting, and (4) normalization. The classification step is where inputoutput parameters are assigned to impact categories. Characterization transforms the classified data according to a number that indicates the contribution to the environmental impact per functional unit (Finnveden et al. 2009; Klöpffer, 1997; Pennington et al. 2004). Weighting is the valuation of the input-output according to the scarceness of a resource and the quality of the resource. Weighting can include the incorporation of social, political, and ethical values for each impact category. The weighting values can be based on decision criteria such as monetization (if someone would pay for the item), panel determination (determined using a survey), and 
the distance to the target (Finnveden et al. 2009; Klöpffer 1997; Pennington et al. 2004). Normalization is the ratio of the total value to the value of the functional unit for a given impact category using reference values. Normalization places the ELCA indicator results into a broader context and gives all of the results a common dimension (Finnveden et al. 2009; Pennington et al. 2004). Multiple impact assessment methods are required because the weighting by each method is different and can give drastically different results (Stavropoulos et al. 2016).

The benefits of using ELCA as a tool in manufacturing include increased manufacturing efficiency and reduced production costs by making changes in the raw materials used, how waste is generated, and how waste is disposed of-especially for smaller companies (Rebitzer et al. 2004). Life-cycle assessment also ensures that no marginal impacts in one area of the environment shift to another, because the assessment examines the entire life cycle of the product (Finnveden et al. 2009; Rebitzer et al. 2004). The assessment also provides the ability to evaluate the material and energy efficiency of a production system and the benchmarks for product optimization (Huntzinger and Eatmon 2009). The application of an ELCA provides businesses with a competitive edge in the marketplace (Miettinen and Hämäläinen 1997; Rebitzer et al. 2004; Stavropoulos et al. 2016). Small companies also benefit from using ELCA in their manufacturing processes by including new product introduction, reducing certification costs, and reducing overhead (Rebitzer et al. 2004). For years, governments such as the United Kingdom, France, Norway, Denmark, the Netherlands, Sweden, and Belgium have supported ELCA studies to inform the development of legislation as well as create criteria for taxes and environmental performance metrics or standards. Life-cycle assessment methodology has also been used to help promote ecolabeling programs and provide consumer information (Miettinen and Hämäläinen 1997).

\subsection{Objective(s)}

This report details the results of a study conducted by a private-public partnership consisting of the US Army Engineer Research and Development Center (ERDC), the Jordan Valley Innovation Center (Missouri State University), and Brewer Science. Brewer Science sought to reduce the environmental impact and increase the energy and manufacturing efficiency associated with manufacturing environmental sensors. ERDC sought to use ELCA diagnostically to highlight which aspects of sensor production 
most contributed to marginal environmental impacts for Brewer Science to optimize their manufacturing process.

\subsection{Approach}

Brewer Science developed carbon nanomaterial-enabled sensors to measure environmental parameters such as temperature and humidity and physical characteristics such as flexibility and deformation. Using nanomaterials allowed miniaturizing the sensors relative to the status quo, and printing the nanomaterial as an ink allowed designing the sensors to fit customizable purposes as well as allowing refinement and scale-up. However, the nanomaterial used could contain impurities that negatively affect performance and the environment. Therefore, this public-private partnership performed an ELCA to make the sensor manufacturing process cleaner and more efficient and to reduce waste-all while improving sensor performance and increasing the scalability of production. This report will be published with a corresponding document focused on practical considerations and recommendations for individuals or companies interested in developing an ELCA for their own products. 


\section{Material and Methods}

\subsection{Sensor devices}

With their unique chemical, physical, mechanical, and electrical properties, carbon nanomaterials, such as carbon nanotubes (CNTs), make for excellent sensing materials. After proper chemical and mechanical processing, CNTs can become printable inks for fabricating sensors using various printing technologies, such as screen printing, ink-jet printing, and Aerosol Jet printing. The CNT-based sensors are resistive-type sensors sensitive to the changes of their surrounding environment. Their electrical resistance changes as conditions in the surrounding environment, such as temperature and humidity, change and as physical bending and flexing of the sensors occur. Different types of sensors using different printing technologies require unique CNT material formulations and sensor designs. Figure 3 presents a representative design of a fully printed sensor device.

Figure 3. Generic structure of a fully printed sensor device with six layers: encapsulant materials; filters or other active materials; sensor material such as carbon nanotubes (CNTs) or graphene; printed conductors such as silver, gold, or copper; isolation or surface modification layers; and substrate such as PET, Kapton, or silicon.

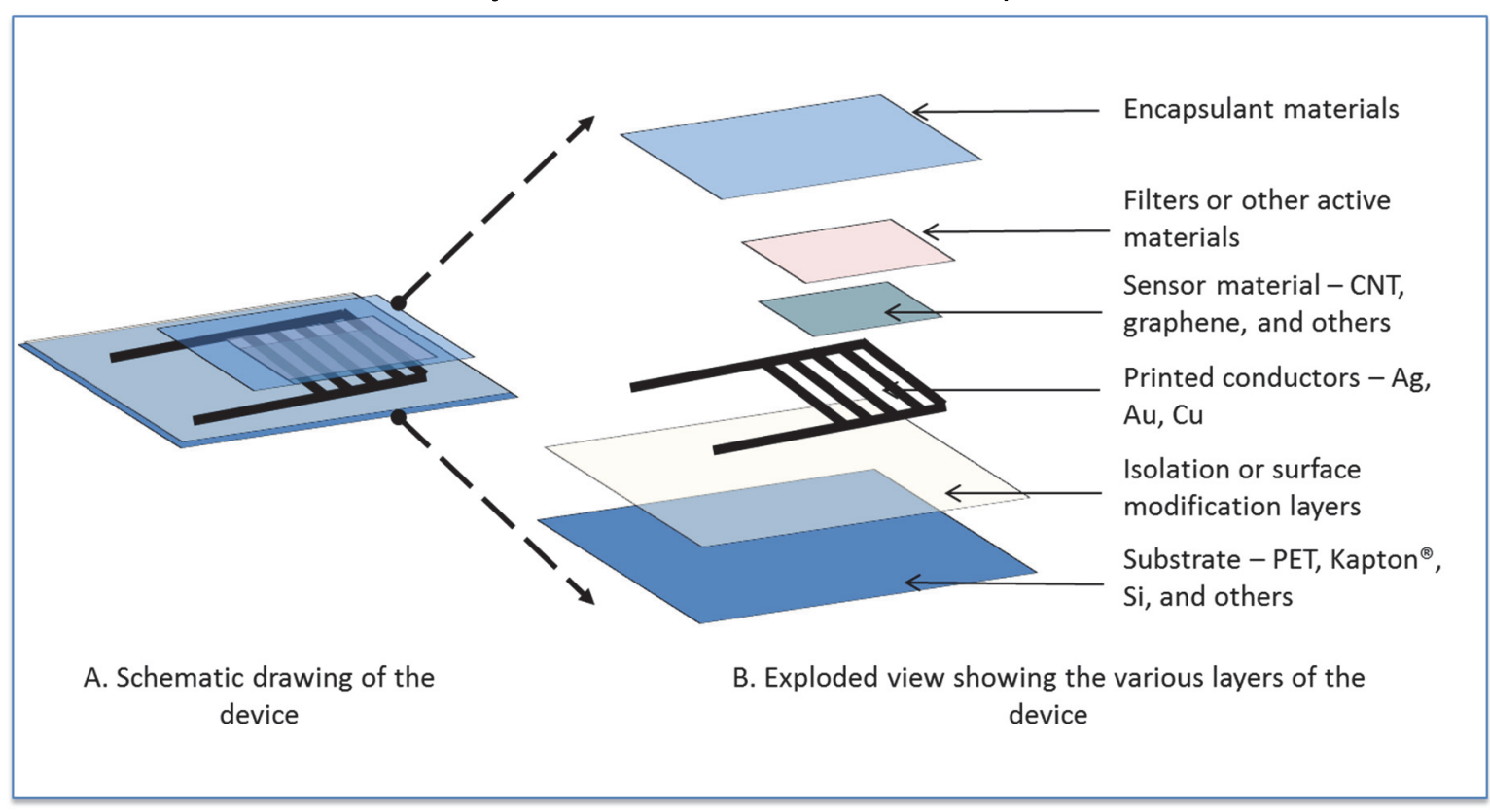

\subsection{CNTRENE 1030 material and sensors}

This evaluation involved case studies on three environmental sensors: a temperature sensor, a moisture sensor, and a flex sensor. Figure 3 
provides the general structure of the sensors. Each sensor used a proprietary CNT-based ink.

This study calculated environmental emissions according to the construction of a representative life cycle inventory (LCI). The LCI contains a record of all inputs and outputs associated with the manufacture of the CNTRENE 1030 material as well as the temperature, moisture, and flex sensors. These inputs and outputs include raw materials, chemicals, electricity, wastes, and energy associated with the transport of materials. Scientists and engineers from Brewer Science answered a questionnaire prepared for this case study; the questionnaire contained data obtained by directly sampling technosphere inputs, the actual manufacturing process (such as materials and power), and outputs or emissions during manufacturing and waste incineration.

Next we carefully constructed the LCI by sampling the actual manufacturing process for technosphere inputs and then computationally constructed it in SimaPro 7.3.3 (PRé Consultants, Netherlands) to include subprocesses associated with the manufacture of the CNTRENE 1030 material and the conductive silver ink as well as the general encapsulation procedure for constructing the printed electronic temperature sensor. We created a gate-to-gate ELCA model with theoretical functional units ranging from approximately $10^{3}$ to $10^{4}$ sensors per day, representing the natural increase in productivity that came with optimizing the manufacturing process. We calculated total emissions for the gate-to-gate assessment using the mass balance of the inventory components as represented through the Eco-Invent 2.2 database (Frischknecht et al. 2005), and we assessed the environmental impacts using commonly available impact assessment models. We occasionally repeated ELCA studies as Brewer Science optimized the production of the CNTRENE 1030 material and the sensors. Here we represent two iterations of the CNTRENE 1030 material as well as three iterations of the temperature, moisture, and flex sensors.

\subsection{Life cycle inventory and life cycle assessment}

Table 1 shows the inventory as categorical inputs for each version of the three sensors and the proprietary ink in the case study. The LCI was conducted using three different impact assessment methods: IMPACT 2002+ (Jolliet et al. 2003), ReCiPe (Goedkoop et al. 2009), and Eco-indicator 99 (Goedkoop and Spriensma 2001). A brief description of each assessment 
method follows, with the relevant environmental impact categories summarized in Table 1.

Table 1. Midpoint and endpoint categories for the three life cycle impact assessment methods used in the case study.

\begin{tabular}{|c|c|c|c|}
\hline \multicolumn{2}{|c|}{ Impact 2002+ } & \multirow{2}{*}{$\begin{array}{c}\text { ReCiPe } \\
\text { Endpoint }\end{array}$} & \multirow{2}{*}{$\begin{array}{c}\text { Eco-indicator } 99 \\
\text { Endpoint }\end{array}$} \\
\hline Midpoint & Endpoint & & \\
\hline Human Toxicity & \multirow{5}{*}{ Human Health } & Climate Change Human Health & Carcinogens \\
\hline Respiratory Effects & & Ozone Depletion & Respiratory Organics \\
\hline Ionizing Radiation & & Human Toxicity & Respiratory Inorganics \\
\hline Ozone Layer Depletion & & Photochemical Oxidant Formation & Climate Change \\
\hline Photochemical Oxidation & & Particulate Matter Formation & Radiation \\
\hline Aquatic Ecotoxicity & \multirow{6}{*}{ Ecosystem Quality ${ }^{1}$} & Ionizing Radiation & Ozone Layer \\
\hline Terrestrial Ecotoxicity & & Climate Change Ecosystems & Ecotoxicity \\
\hline Aquatic Acidification & & Terrestrial Acidification & $\begin{array}{c}\text { Acidification/ Eutrophica- } \\
\text { tion }\end{array}$ \\
\hline Aquatic Eutrophication & & Freshwater Eutrophication & Land Use \\
\hline Terrestrial Acid/Nutr & & Terrestrial Ecotoxicity & Minerals \\
\hline Land Occupation & & Freshwater Ecotoxicity & Fossil Fuels \\
\hline Global Warming & Climate Change & Marine Ecotoxicity & \\
\hline Non-Renewable Energy & \multirow{2}{*}{ Resources } & Agricultural Land Occupation & \\
\hline Mineral Extraction & & Urban Land Occupation & \\
\hline & & Natural Land Transformation & \\
\hline & & Metal Depletion & \\
\hline & & Fossil Depletion & \\
\hline
\end{tabular}

1 Also includes ozone layer depletion and photochemical oxidation

\subsubsection{IMPACT 2002+}

We developed the IMPACT 2002+ assessment method (Jolliet et al. 2003) using a combination of four methods: the IMPACT 2002, Eco-indicator 99, CML, and IPCC. It includes both midpoint and endpoint assessment, where midpoint categories are grouped into four endpoint damage categories (Table 1). We used IMPACT 2002+ V2.10 for this study, as a component of the SimaPro software package. The model includes damage assessment, normalization, weighting, and the addition of categories. We set all weighting of endpoint categories to a default of 1 (Pré Consultants 2010b).

\subsection{2 $\quad \mathrm{ReCiPe}$}

The ReCiPe method (Goedkoop et al. 2009) was developed by RIVM, CML, Pré Consultants, Radbound Universiteit Nijmegen, and CE Delft. 
The method can conduct analysis using midpoints or endpoints. The data analysis presented here were conducted using the endpoint option (Table 1). The ReCiPe method incorporates three human perspectives: individualist, hierarchist, and egalitarian. The data presented here were analyzed with the hierarchist perspective. This method also includes damage assessment, normalization, weighting, and the addition of categories. This report presents the weighting factors belonging to the hierarchist perspective and uses ReCiPe Endpoint (H) V1.06 as a component of the SimaPro software package (Pré Consultants 2011).

\subsubsection{Eco-indicator 99}

The Eco-indicator 99 method (Goedkoop and Spriensma 2001) is an endpoint assessment method where perspective weighting occurs at the endpoint level (Table 1). The model includes damage assessment, normalization, weighting, and addition of categories. The normalization performed for this assessment is presented below. Weighting can be performed using the individualist, hierarchist, and egalitarian perspectives. The data analysis presented here used the default hierarchist perspective. This study used Eco-indicator $88(\mathrm{H}) \mathrm{V} 2.08$ as a component of the SimaPro software package (Pré Consultants 2010a).

This report discusses only the results of the IMPACT2002+ method in detail. Impact2002+ is a combination of four methods: IMPACT 2002, Ecoindicator 99, CMl (Guinee et al. 2002), and IPCC. The IMPACT2002+ method gives both midpoint and endpoint results. Midpoints provide greater detail into a wide range of impacts and can evaluate total energy used, water consumed, and $\mathrm{CO}_{2}{ }^{*}$ equivalents. The midpoint analysis gives lower uncertainty in results. However, agreement in the results obtained from the ReCiPe and Eco-Indicator 99 LCIA methods provided a relative verification of the IMPACT2002+ results. Portions of this information were previously published by Chappell et al. (2017).

*. For a full list of the spelled-out forms of the chemical elements used in this document, please refer to US Government Publishing Office Style Manual, 31st ed. (Washington, DC: US Government Publishing Office, 2016), 265, https://www.govinfo.gov/content/pkg/GPO-STYLEMANUAL-2016/pdf/GPOSTYLEMANUAL-2016.pdf. 


\section{Results}

\subsection{CNTRENE 1030 material}

While the Eco-LCA study was limited to the portions of CNTRENE 1030 material development directly under Brewer Science's control, hypothetically including the manufacture of the raw CNT materials (a process controlled and performed by outside producers) produced a negligible difference in the outcome of the Eco-LCA due to the overall small quantity of CNTRENE 1030 material produced annually. Given that the exact CNT synthesis technique is often proprietary, we considered the equivalent representation of CNT synthesis as carbon black powder to be a conservative estimate of the associated environmental impacts.

Computed characterization factors and damages for all midpoint impact categories for CNTRENE 1030 material production were dominated (74\%) by the production of the derivatized CNT suspension. Figure 4A shows that the majority of impacts for the original CNTRENE 1030 material, developed in 2014, arose from the disposal of CNT wastes. As required by local regulatory guidelines and EPA LoREX at 40 CFR 723.50*, Brewer Science incinerates all residual waste CNT suspensions as hazardous waste. Our calculations estimated that the environmental impacts originated from the fossil fuels and other energy resources (Figure 5) required to power such high-temperature incineration as well as the release of greenhouse-type combustion products into the atmosphere. The environmental impact of synthesizing the CNT powder, as emphasized by Eckelman et al. (2012), was negligible relative to incineration of the CNT wastes.

*. Toxic Substances Control Act of 1976, 15 USC. § 723.50 (2019). https://www.govinfo.gov/content/pkg/CFR-2019-title40-vol34/pdf/CFR-2019-title40-vol34-part723-subpartB.pdf. 
Figure 4. Calculated environmental impacts for (A) original and (B) optimized CNTRENE 1030 material using the IMPACT2002+ model.
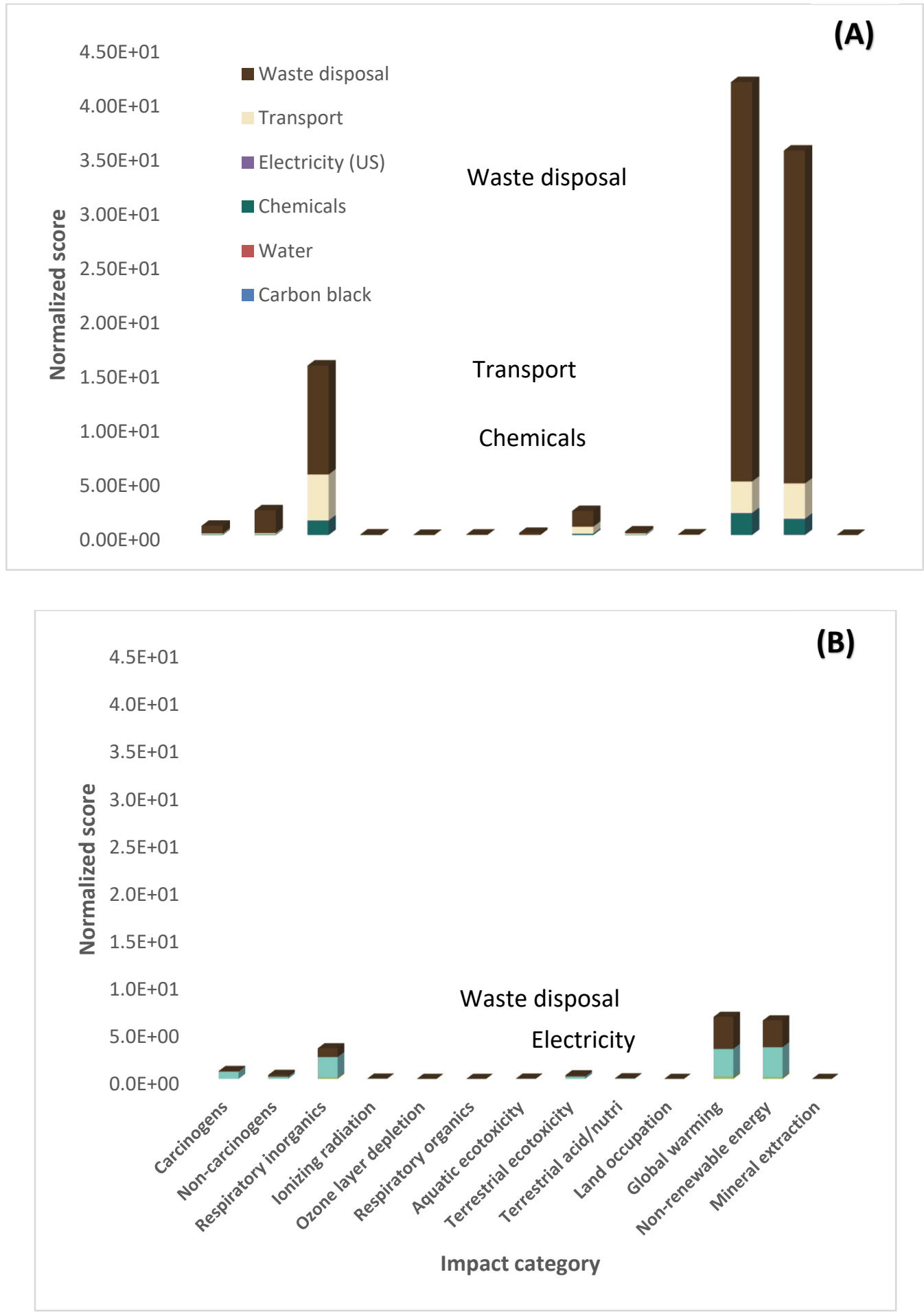

In light of these impacts, Brewer Science improved the efficiency of manufacturing the CNTRENE 1030 material by reducing water usage and, consequently, waste generation by over $95 \%$. Thus, on the basis of the 
normalized impact score, Eco-LCA modeling (Figure 4B) showed that optimizing CNTRENE 1030 material production resulted in substantial absolute reductions in emissions potentially contributing to climate change and reductions in resource depletion-associated impacts by approximately one order of magnitude. Furthermore, optimization of the CTNRENE 1030 material shifted the relative environmental burden from the energy consumption associated with hazardous waste incineration to the electricity used in the manufacturing process.

Figure 5. Pie chart representing the calculated process contributions to the environmental impacts for CNTRENE 1030 material.

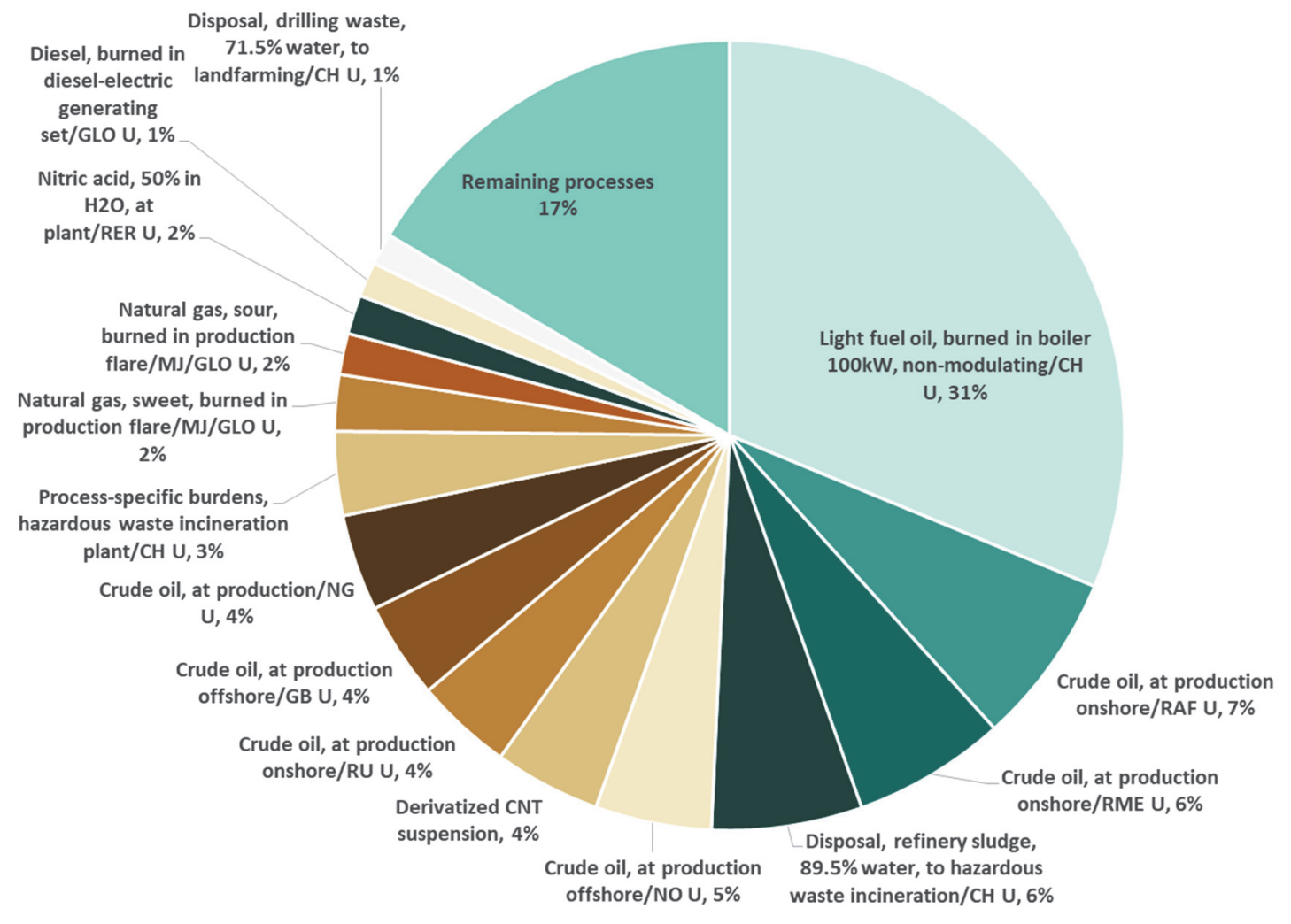

\subsection{Temperature sensor}

Figure 6 shows the ELCA results for the production prototype (version 1) of the temperature sensor. Given the very small quantities of materials used in constructing the sensor, and the fact that Brewer Science had completely sealed all systems (to eliminate occupational exposures) associated with handling the raw and formulated CNT products and wastes, the absolute environmental impacts calculated from the ELCA model related to the sensor's manufacture were relatively low. Dominant environmental 
impacts, such as greenhouse gas emissions, natural resource depletions, and other inorganic emissions linked to respiratory hazards, were associated with the use of compressed gas and electrical power requirements for creating the temperature sensor, and they represented the bulk of the modeled environmental impacts, reflecting the inherent challenges in adapting conventional manufacturing processes to next-generation materials. Electricity accounted for $63-68 \%$ of the score for the respiratory inorganics, global warming, and nonrenewable energy impact categories. Processes contributing to these impacts (Figures 7-9) resembled those calculated for the CNTRENE 1030 material. Thus, the ELCA identified the opportunities to improve energy and cost efficiencies for this particular process.

Figure 6. Normalized impact scores for the temperature sensor, version 1, using IMPACT $2002+$ model.

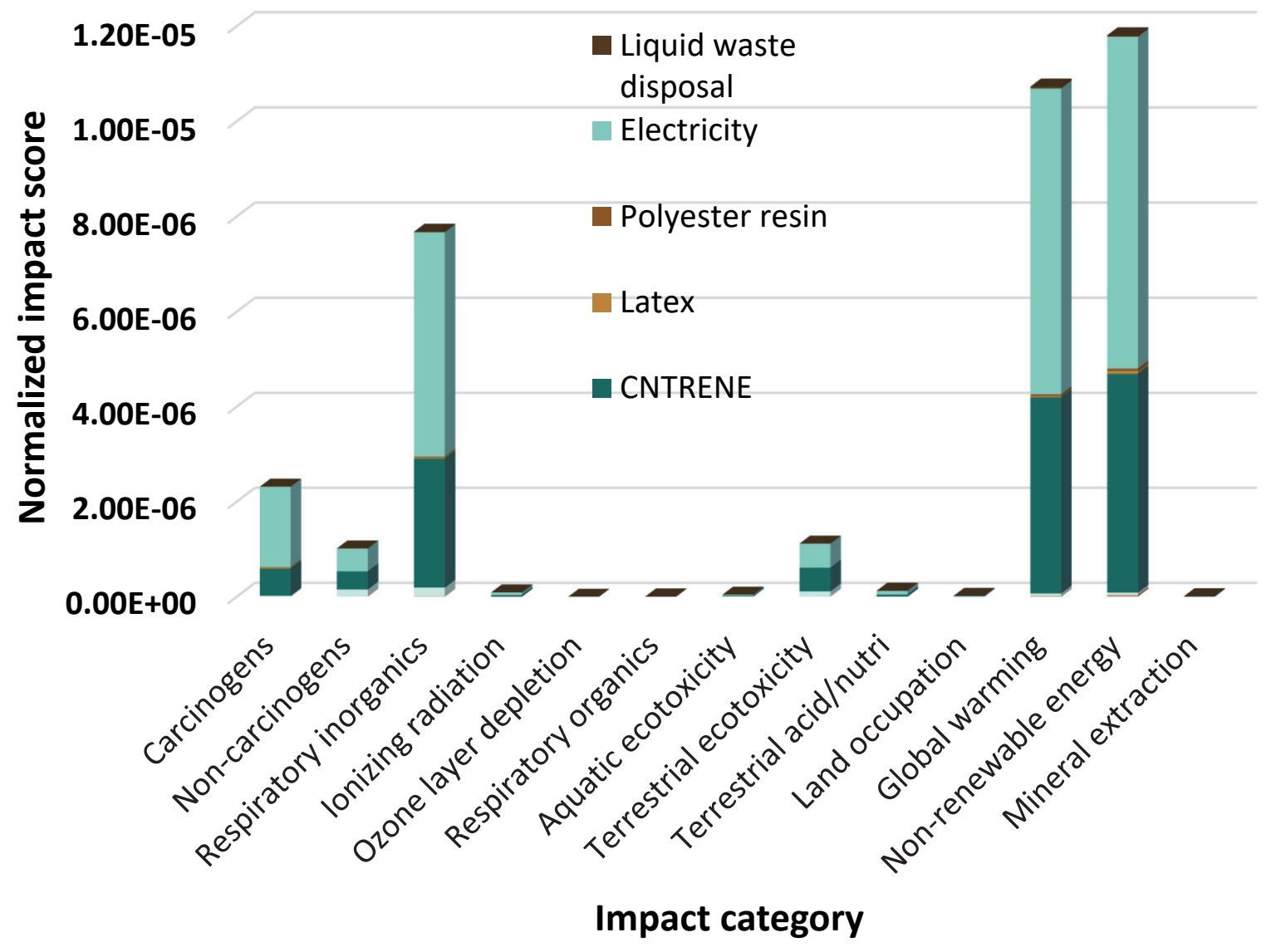


Figure 7. Pie chart representing the calculated process contributions to the nonrenewable energy environmental impacts (IMPACT2002+) for the production of the CNTRENE 1030 material-based temperature sensor (version 1).

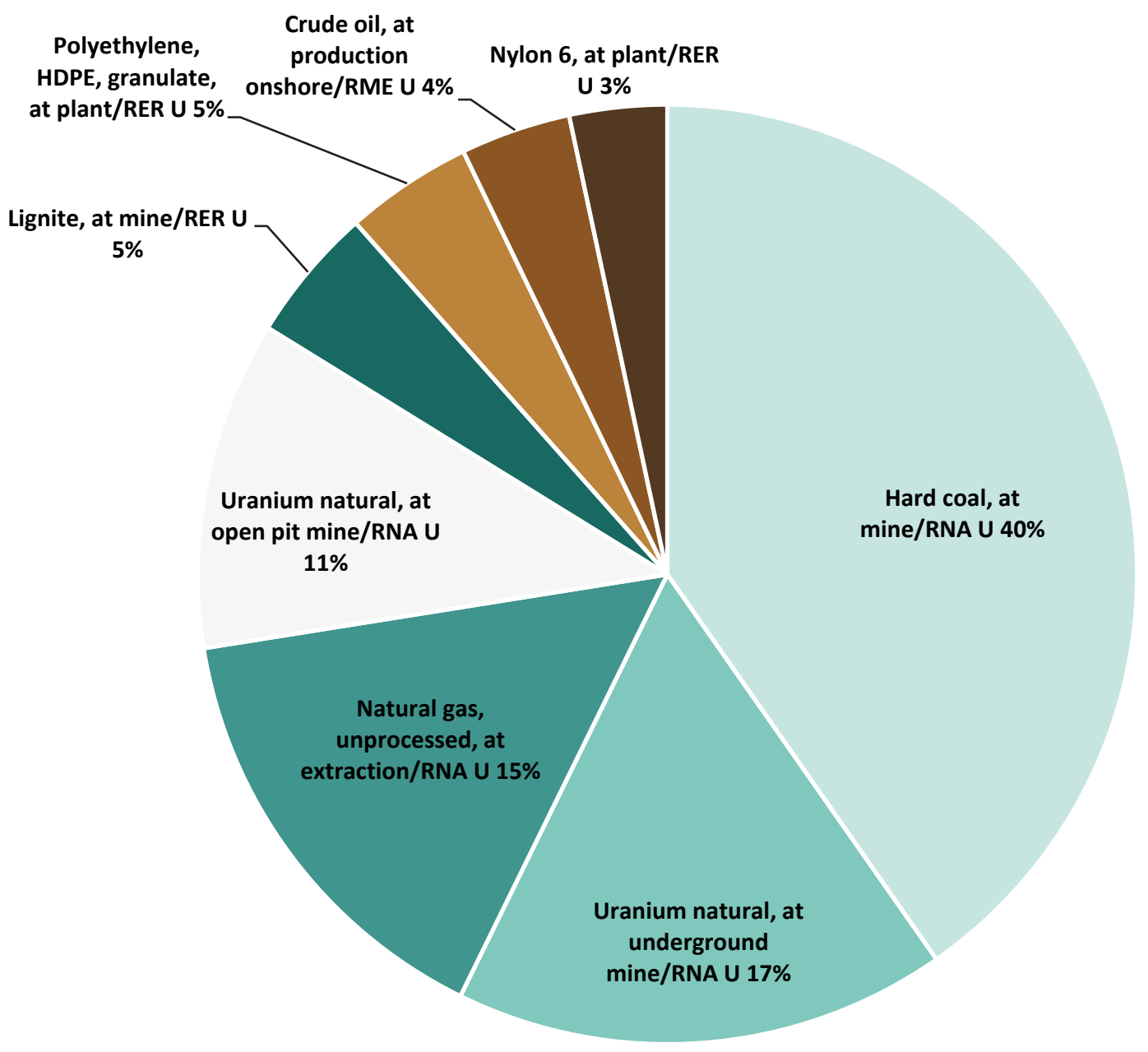


Figure 8. Pie chart representing the calculated process contributions to the global warming environmental impacts (IMPACT2002+) for the production of the

CNTRENE 1030 material-based temperature sensor (version 1).

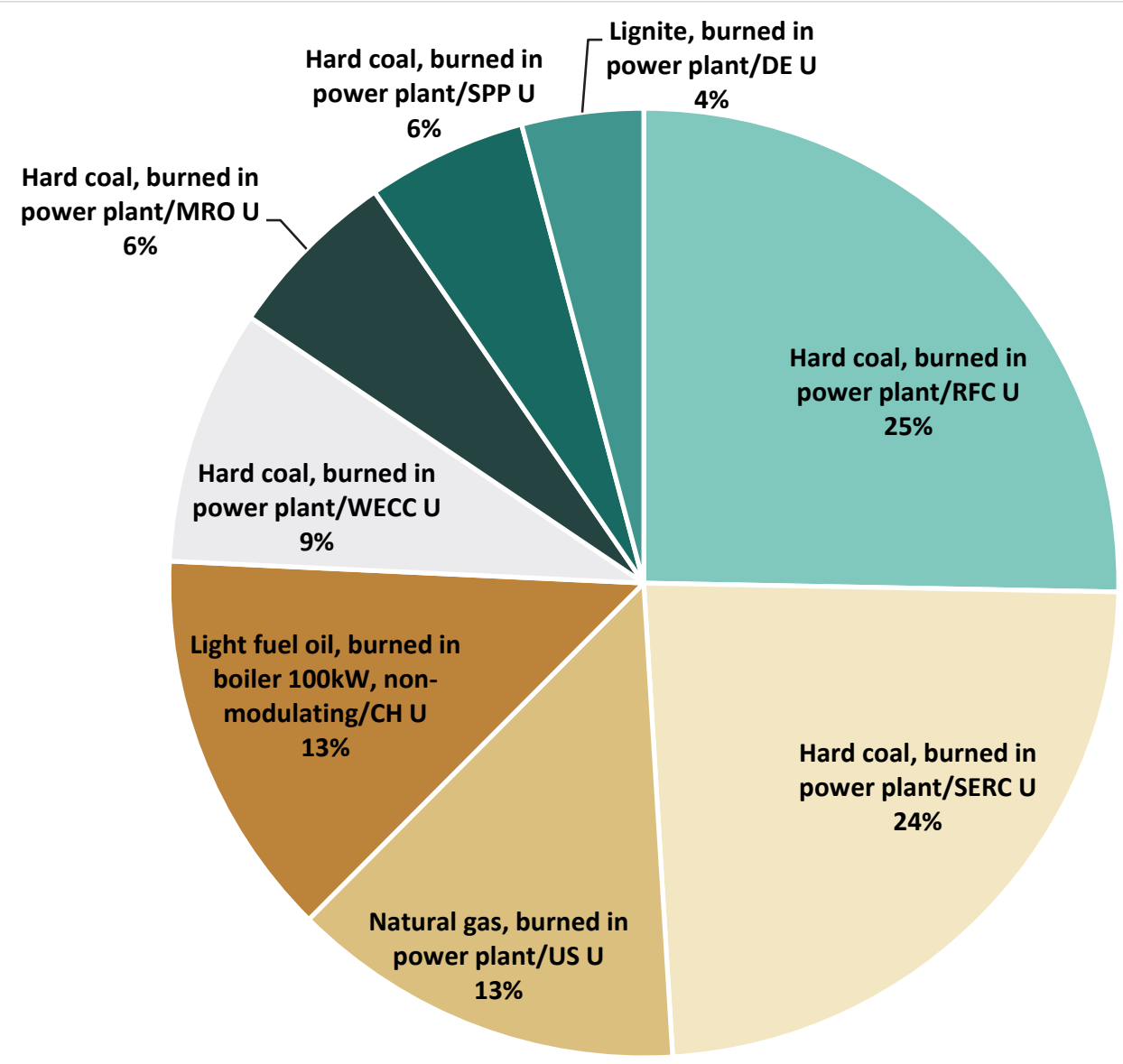


Figure 9. Pie chart representing the calculated process contributions to the respiratory inorganics environmental impacts (IMPACT2002+) for the production of the CNTRENE 1030 material-based temperature sensor (version 1).

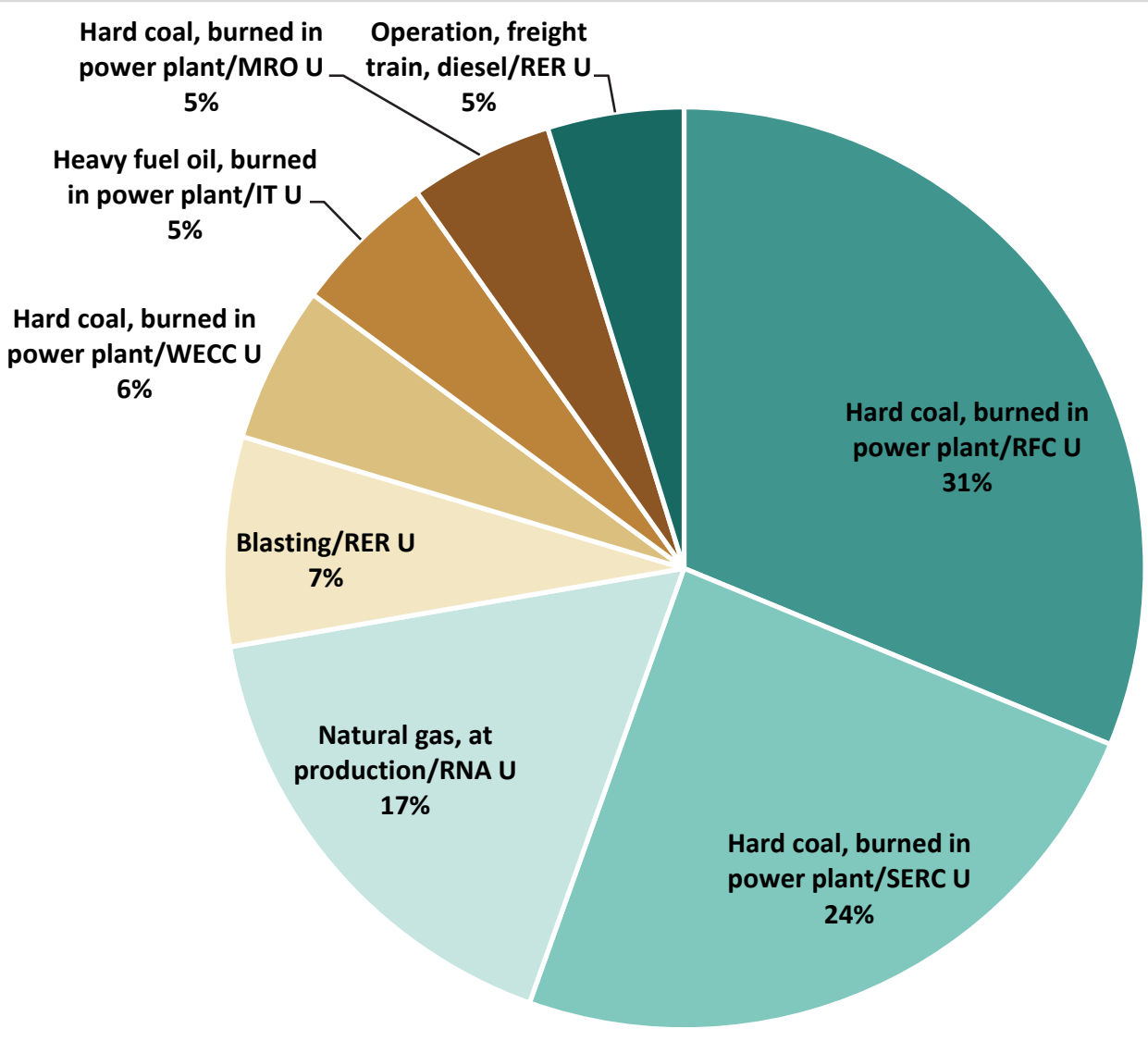

Partial optimization of the temperature sensor platform (Figure 10) showed a decrease of approximately one order of magnitude in the total normalized impact score for the IMPACT2002+ method, from approximately $10^{-5}$ to $10^{-6}$. Similar decreases occurred for the other LCIA methods. Also evident is the shift of the impact score profile for the second version of the temperature sensor relative to the original version, with the emissions contribution by electricity reduced by the nearly $190 \mathrm{kWh}^{*}$ reduction from version 1 to version 2 . With this reduction in emissions generated from electricity (composing approximately $45 \%$ of the environmental impact), impacts associated with compressed gas generation became more significant in the partial optimized version of the temperature sensor,

*. For a full list of the spelled-out forms of the units of measure used in this document, please refer to US Government Publishing Office Style Manual, 31st ed. (Washington, DC: US Government Publishing Office, 2016), 248-52, https://www.govinfo.gov/content/pkg/GPO-STYLEMANUAL-2016/pdf/GPOSTYLEMANUAL-2016.pdf. 
contributing on average another $45 \%$ of the total environmental impact. The remaining $10 \%$ of the impacts resulted mostly from the silver ink, the polyester used in the CNTRENE 1030 material packaging, and the latex gloves used as protective equipment for workers. The process contribution plots were similar for the original and partially optimized versions of the sensors, indicating that reductions in the impact scores were solely a function of Brewer Science reducing energy inefficiencies in the manufacturing process.

Figure 10. Normalized impact scores for the temperature sensor, version 2, using IMPACT $2002+$ model.

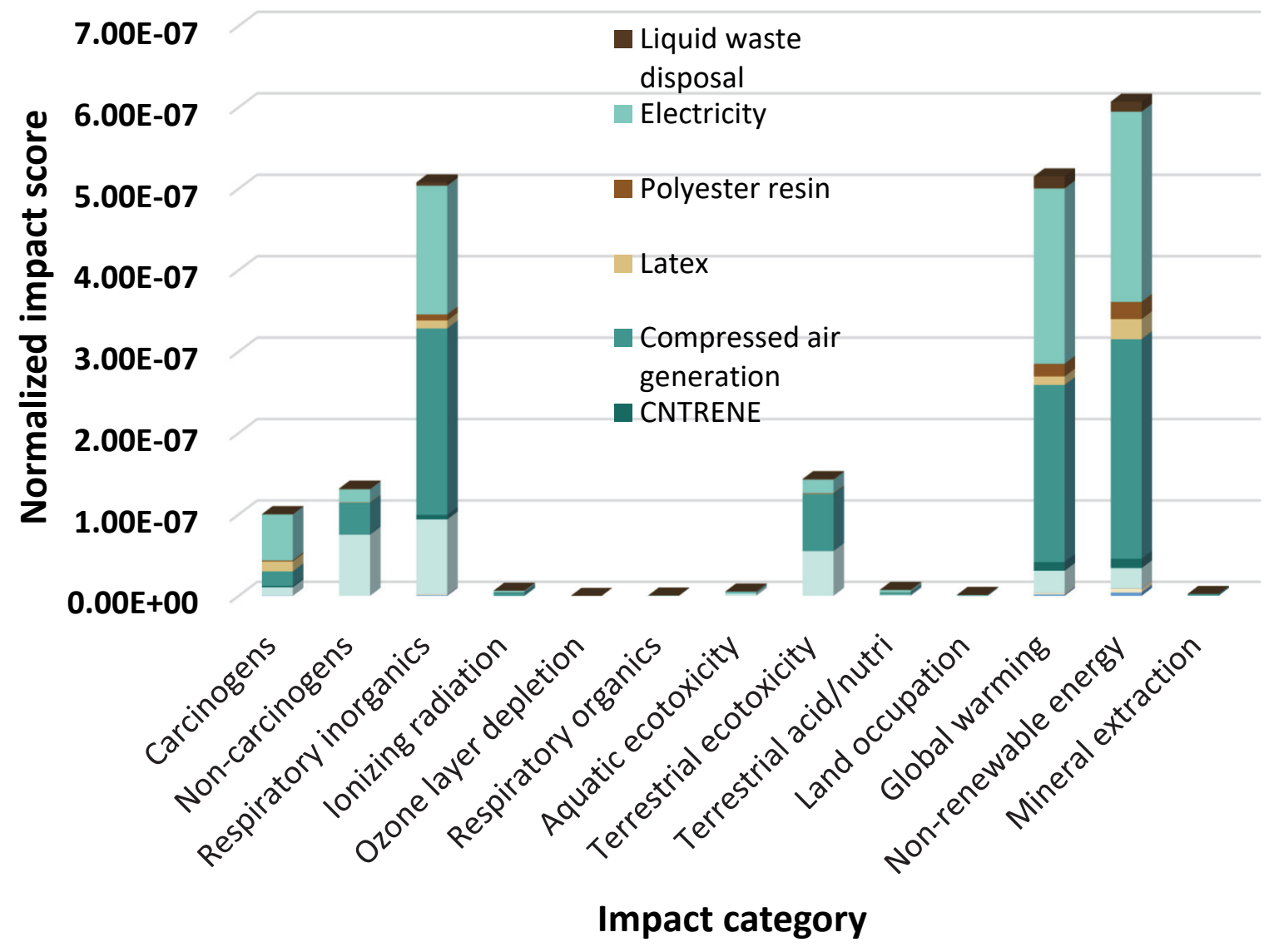

The results for the fully optimized temperature sensor (version 3) showed generally another order of magnitude decrease in the scores across the different environmental impact categories (Figure 11) representing an overall 100-fold decrease among the different impact categories from the original product. There was a noticeable shift in the impact profile of the optimized temperature sensor from version 1 to version 2, with slightly higher relative impacts from inorganic emissions associated with respiratory hazards 
than from greenhouse gases and non-renewable energy resource usage. Most of the impact resulted from the ink used in the fully optimized version of the temperature sensor and contributed $75-88 \%$ of the impacts among the three major impact categories. Considering the process contribution plots (Figures 12-14), the main impacts in the fully optimized temperature sensor were attributed to the production of adipic acid, xylene, and propylene as well as the energy and transport costs in the production of the thermal ink.

Figure 11. Normalized impact scores for the temperature sensor, version 3, using IMPACT 2002+ model

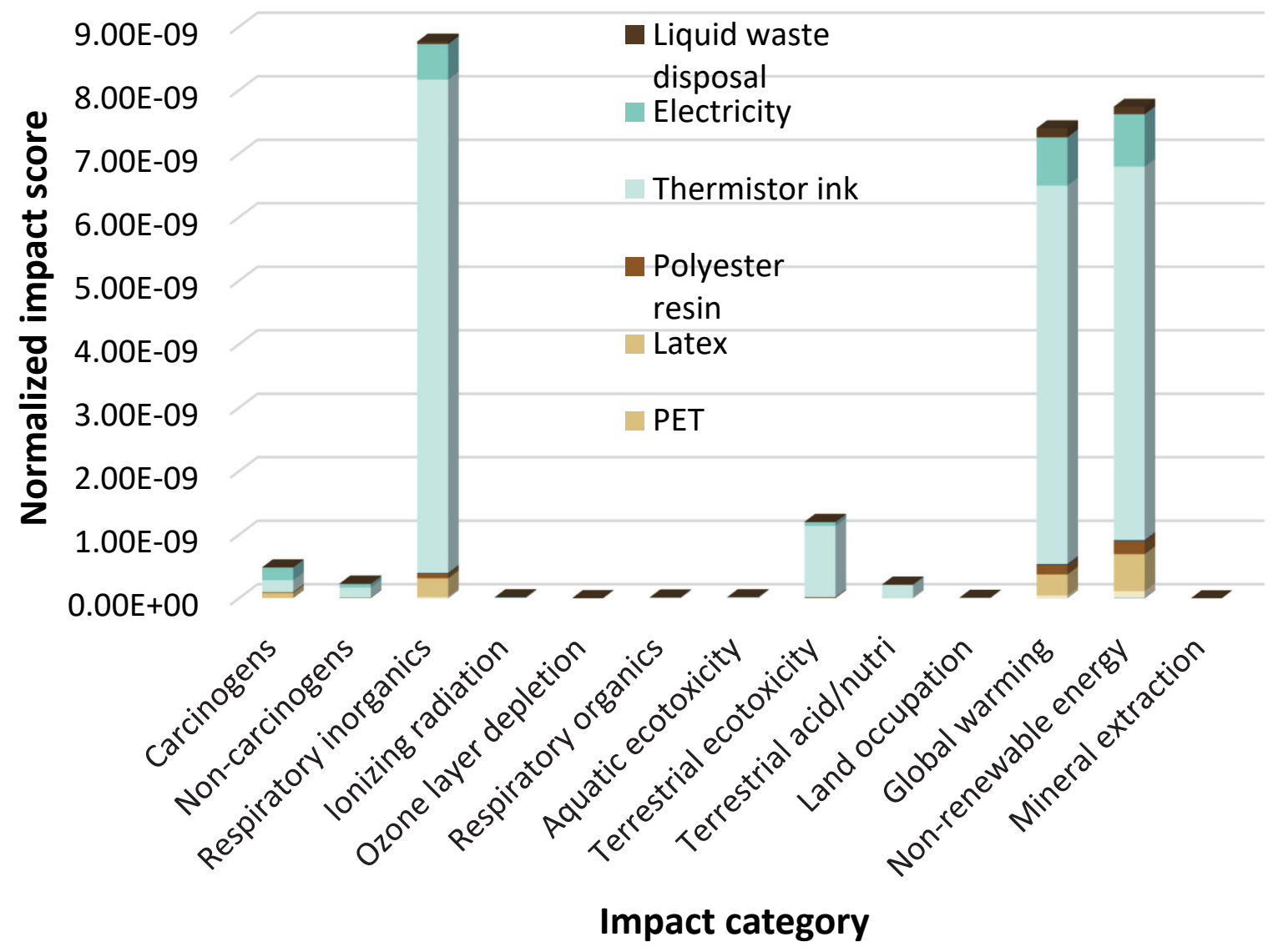


Figure 12. Pie chart representing the calculated process contributions to the respiratory inorganics environmental impacts (IMPACT2002+) for the production of the CNTRENE 1030 material-based temperature sensor (version 3).

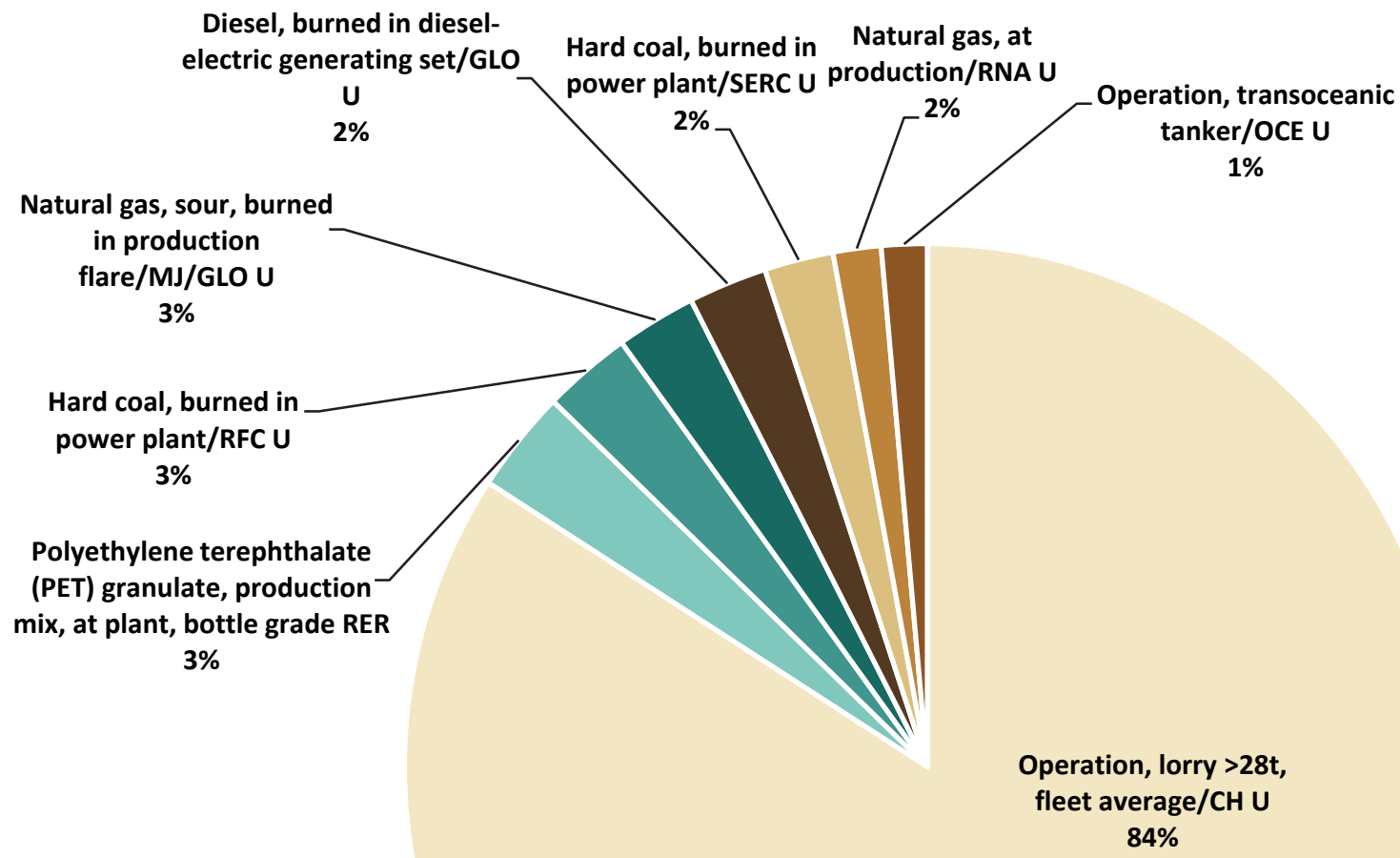


Figure 13. Pie chart representing the calculated process contributions to the global warming environmental impacts (IMPACT2002+) for the production of the CNTRENE 1030 material-based temperature sensor (version 3).

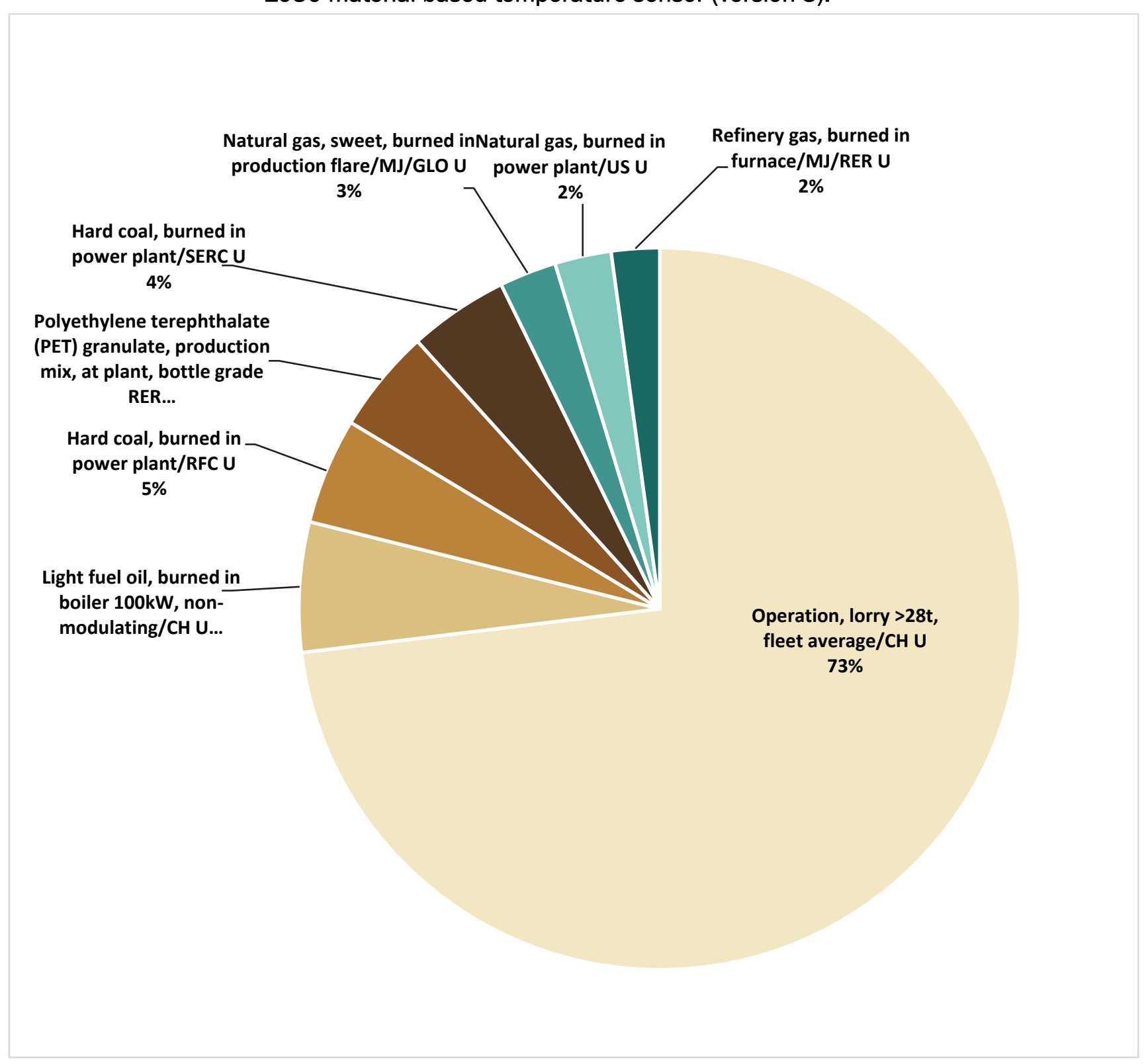


Figure 14. Pie chart representing the calculated process contributions to the nonrenewable environmental impacts (IMPACT2002+) for the production of the CNTRENE 1030 material-based temperature sensor (version 3).

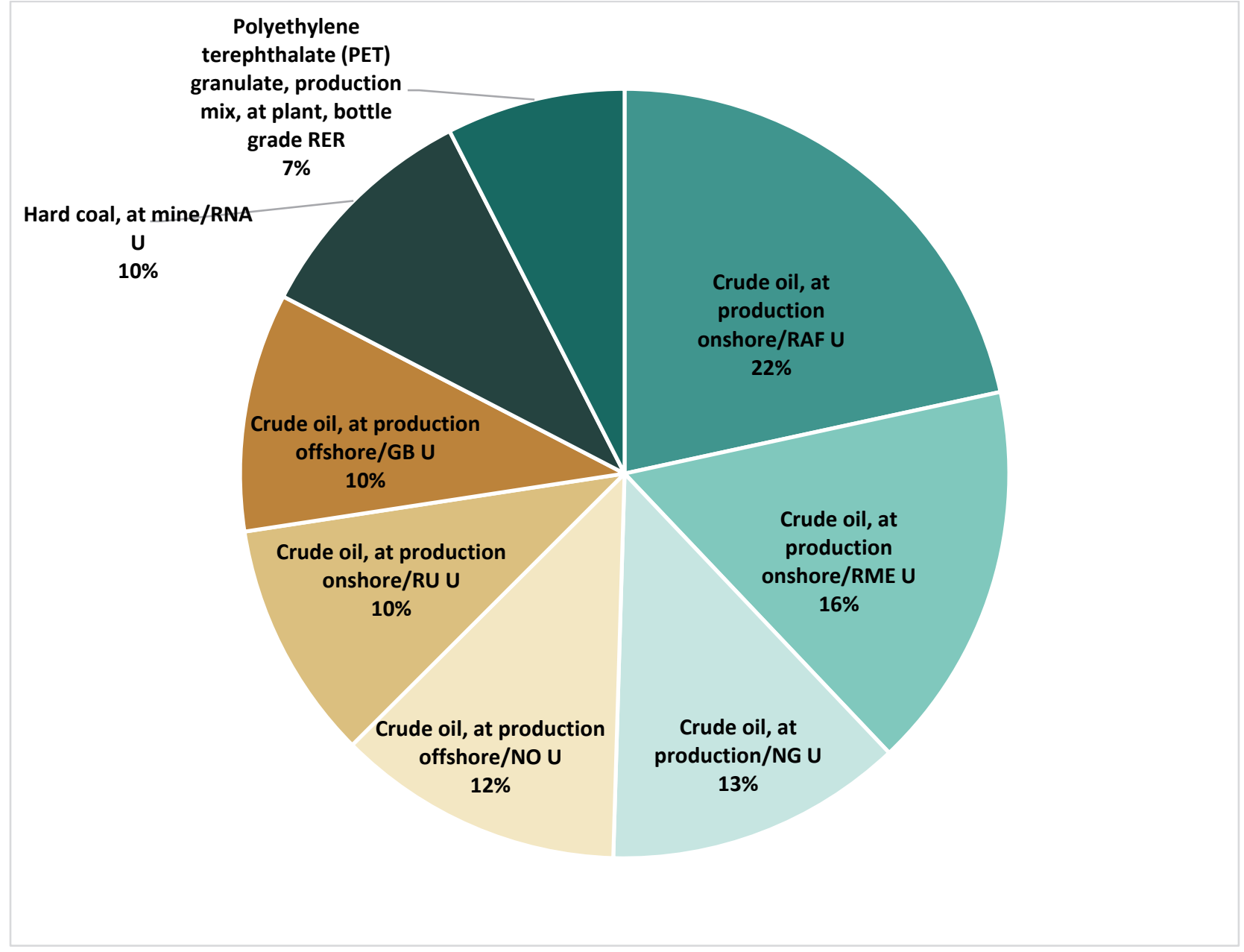

\subsection{Flex sensor}

Overall, the impact scores among the different environmental impact categories for the flex sensor resembled the temperature sensor-on the order of $10^{-5}$. The original version of the flex sensor (version 1 ) gave a similar environmental impact profile to the temperature sensor, with the environmental impacts $(73-85 \%)$ dominated by the electrical power requirements for manufacturing the device (Figure 15). The calculated scores for the partially optimized version of the flex sensor (version 2) were reduced by approximately one order of magnitude compared to the original device. In spite of reducing the electrical usage by $190 \mathrm{kWh}$ for version 2 (Figure 16), electricity generation continued to be the most impact inventory item, contributing $57-75 \%$ of the total impact among the three main impact categories. For the ELCA for the fully optimized flex sensor (Figure 17), the 
impact profile remained relatively similar in spite of showing a substantially reduced absolute impact score $\left(10^{-9}\right)$. The greatest reductions in emissions apparently arose from eliminating the need for compressed air generation reductions generally in marginal environmental impacts, with the scores for the different environmental impact categories decreasing by another order of magnitude, representing, in total, a 100- to 1000-fold reduction among each category. Calculations showed Brewer Science had optimized the sensor production to the point that the greatest contribution to environmental impact came from the electricity used during the manufacturing process (Figure 18).

Figure 15. Normalized impact scores for the flex sensor, version 1, using IMPACT 2002+ model.

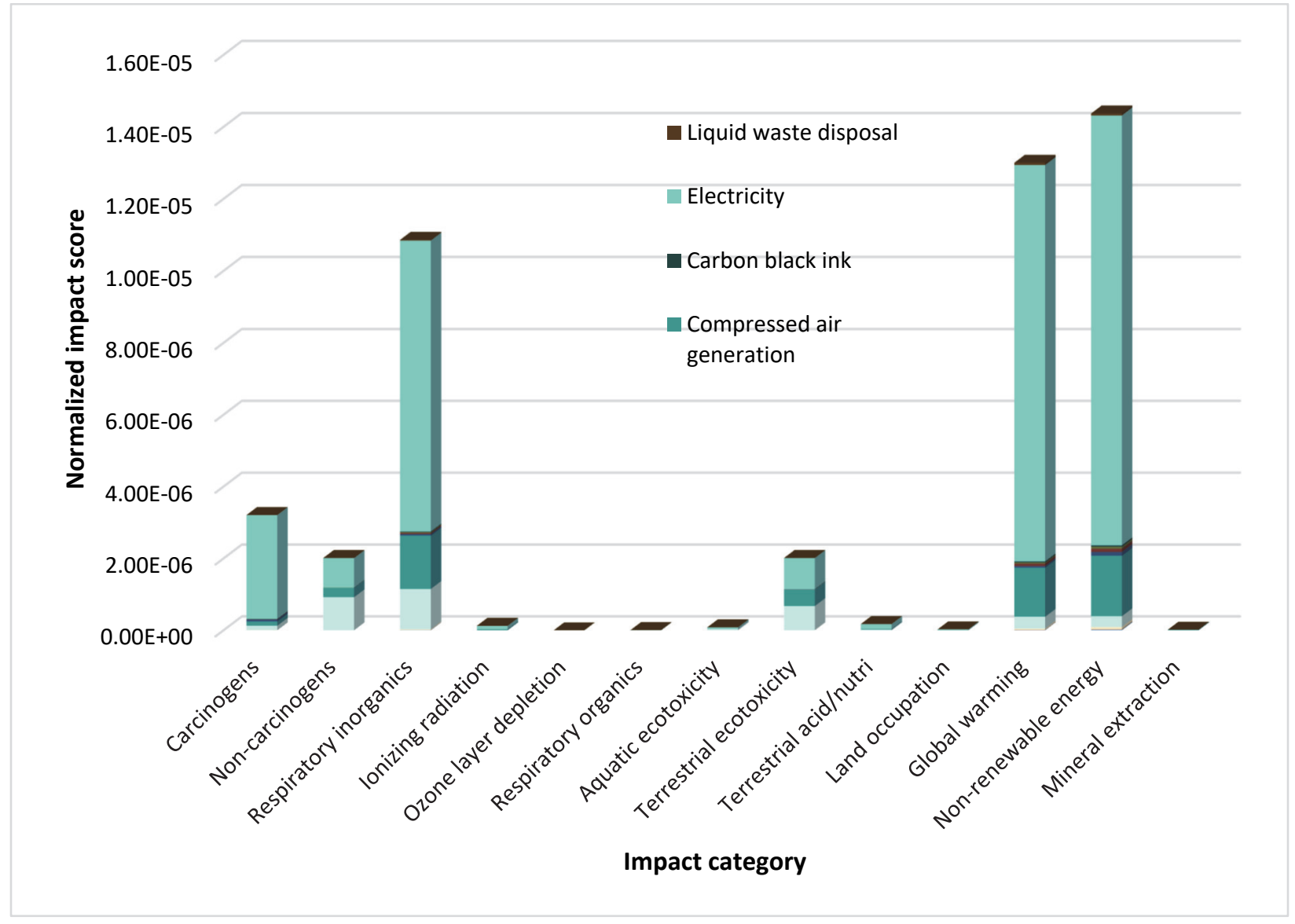


Figure 16. Normalized impact scores for the flex sensor, version 2, using IMPACT 2002+ model.

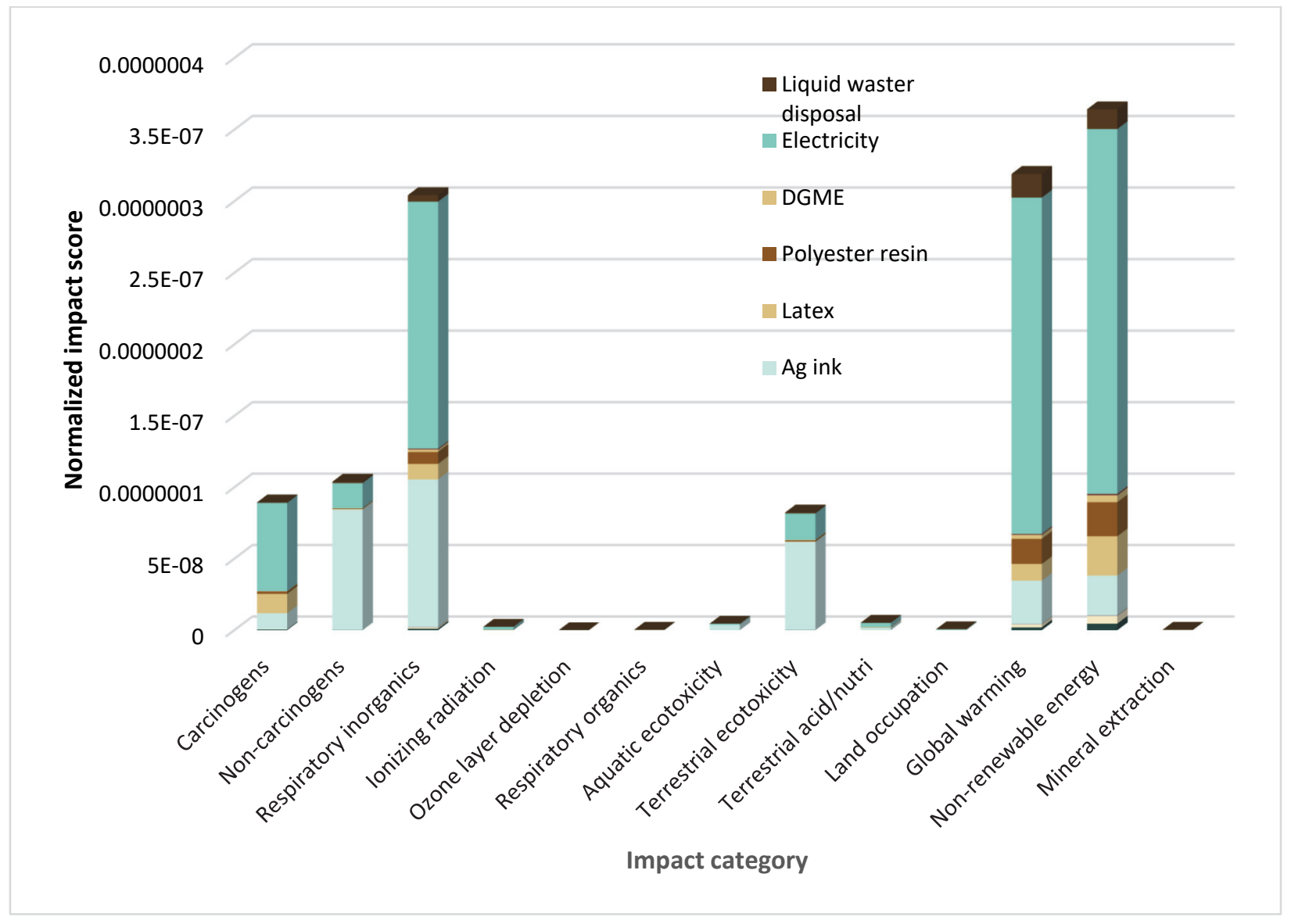


Figure 17. Normalized impact scores for the flex sensor, version 3, using IMPACT 2002+ model.

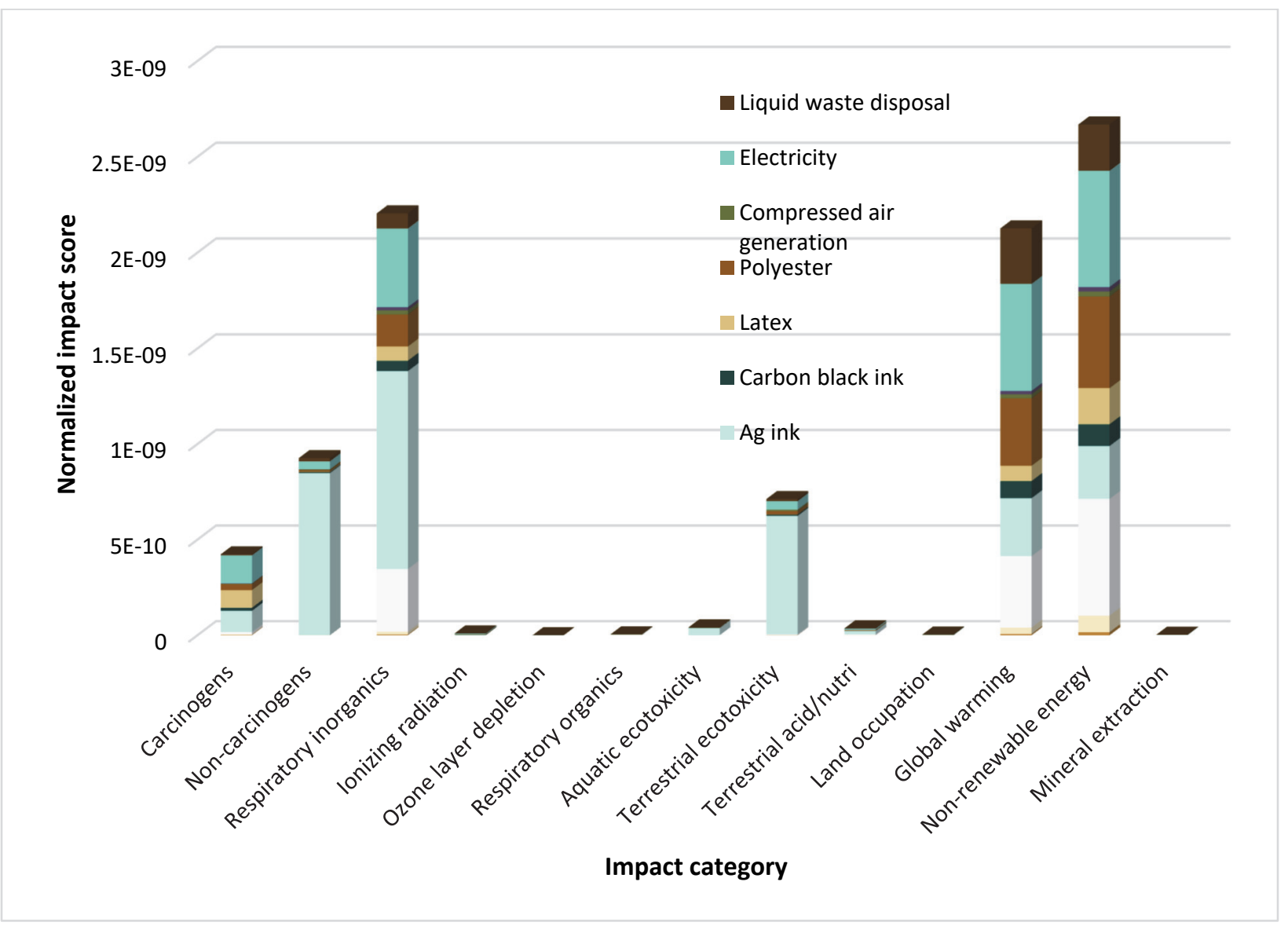


Figure 18. Pie chart representing the calculated process contributions to the global warming environmental impacts (IMPACT2002+) for the production of the carbonaceous nanomaterial-based flex sensor (version 3 ).

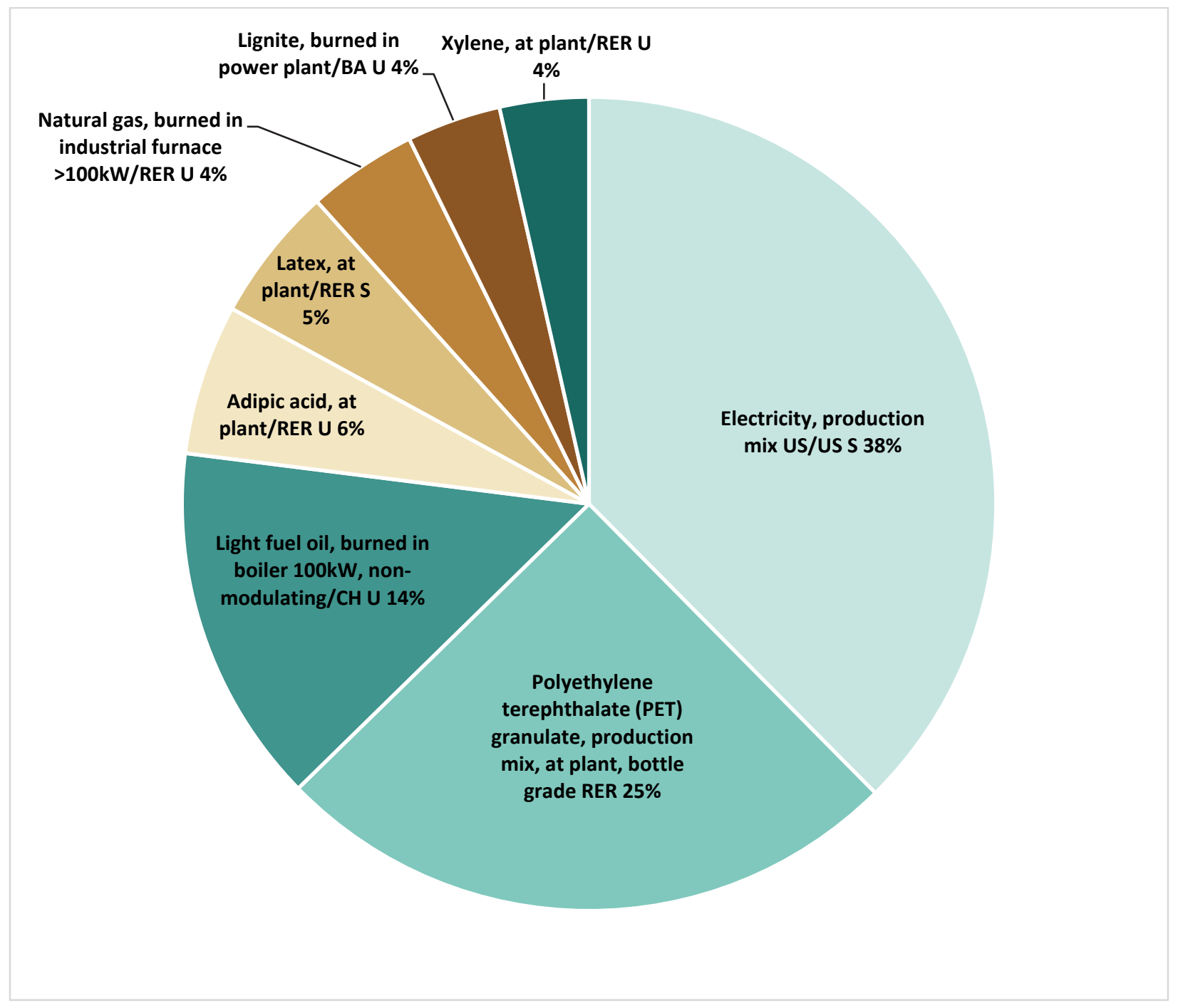

\subsection{Moisture sensor}

The environmental impact profile for the original moisture sensor production prototype (Figure 19) resembled the temperature sensor. However, most of the environmental impact originated from emissions associated with manufacturing the screen-printed thermistor ink, compressed air generation, and electricity (Figure 20). From the partially optimized moisture sensor (version 2), we observed a reduction of approximately one order of magnitude in the device's overall environmental impact scores, particularly for the global warming and nonrenewable energy impact categories (Figure 21). At this stage in the device's development, partial optimization altered the impact profile so that the greatest impacts resulted 
from the compressed air generation (53-64\%) and the electricity (1320\%), among the three main impact categories. Thus, the sensor had been optimized to the point that impacts had reached their threshold according to the efficiency of the equipment used in the production. The fully optimized moisture sensor showed an approximate 100-fold reduction in the scores representing the difference in environmental impact categories from the original device (Figure 22). However, the main inventory component contributing to the impacts was the CNTRENE 1030 material, which was attributed to the fossil fuel consumed during the manufacturing of the material and its transportation to Brewer Science's facility.

Figure 19. Normalized impact scores for the moisture sensor, version 1, using IMPACT 2002+ model.

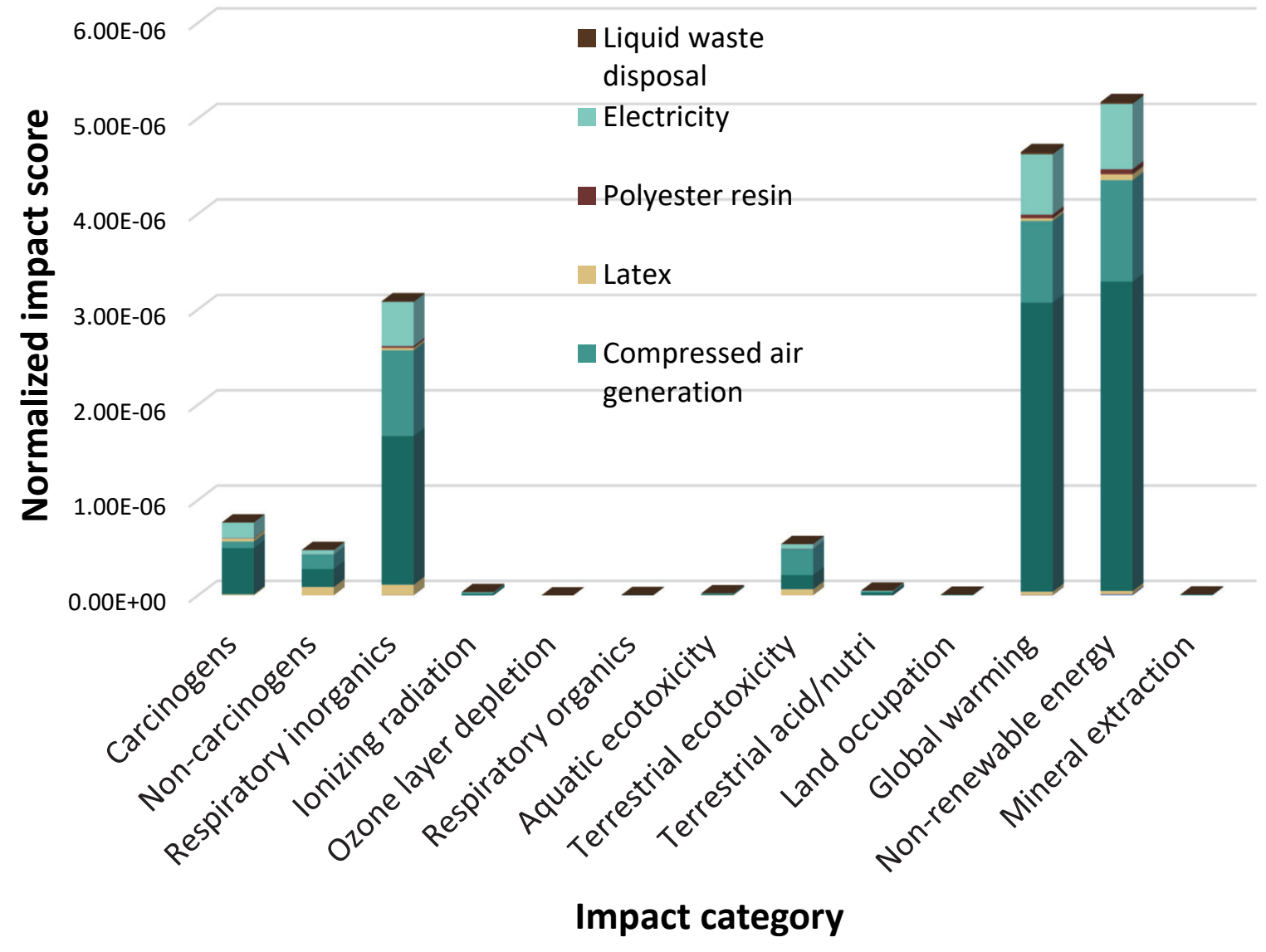


Figure 20. Pie chart representing the calculated process contributions to the nonrenewable energy environmental impacts (IMPACT2002+) for the production of the CNTRENE 1030 material-based moisture sensor (version 1).

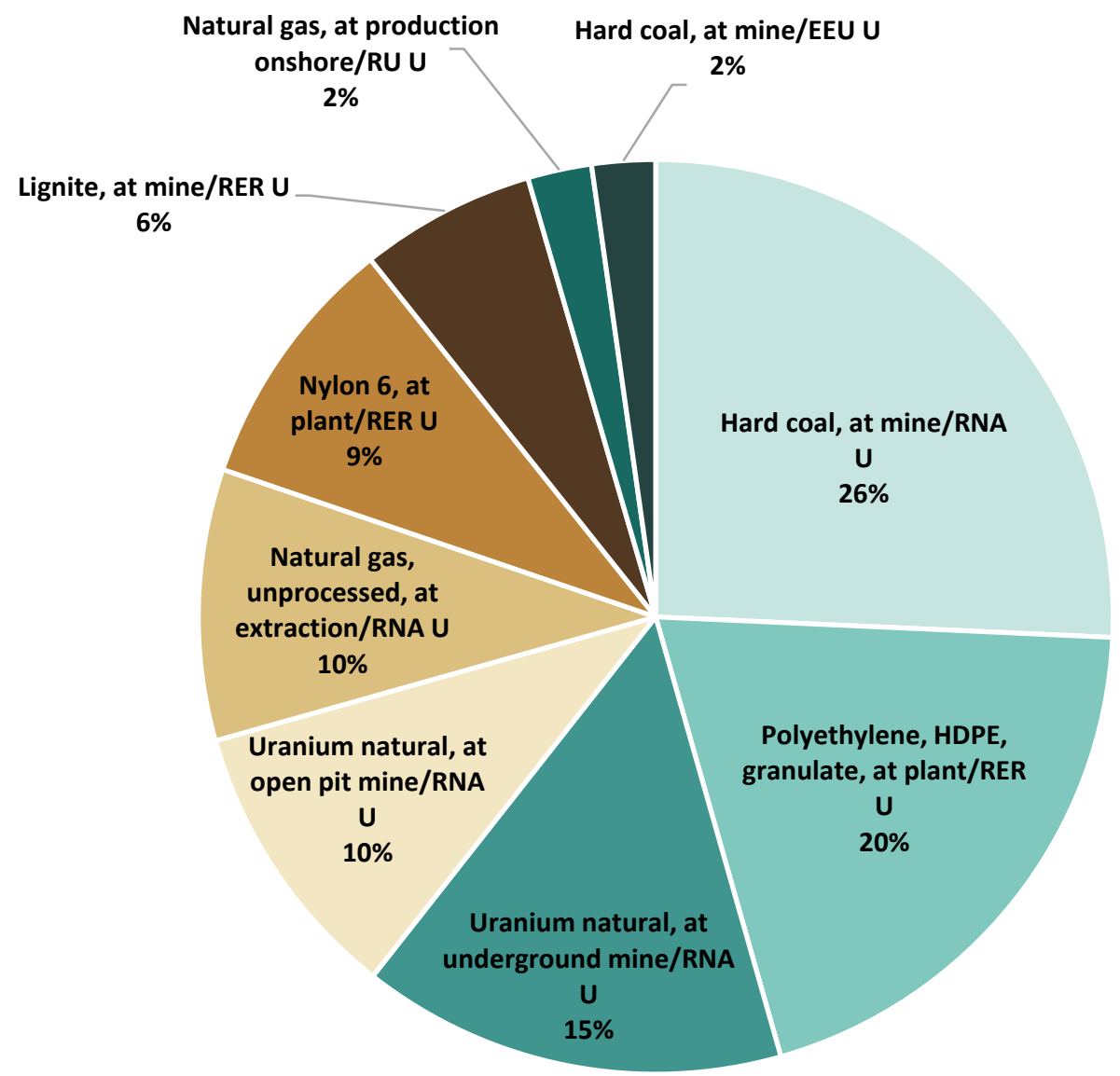


Figure 21. Normalized impact scores for the moisture sensor, version 2, using IMPACT 2002+ model.

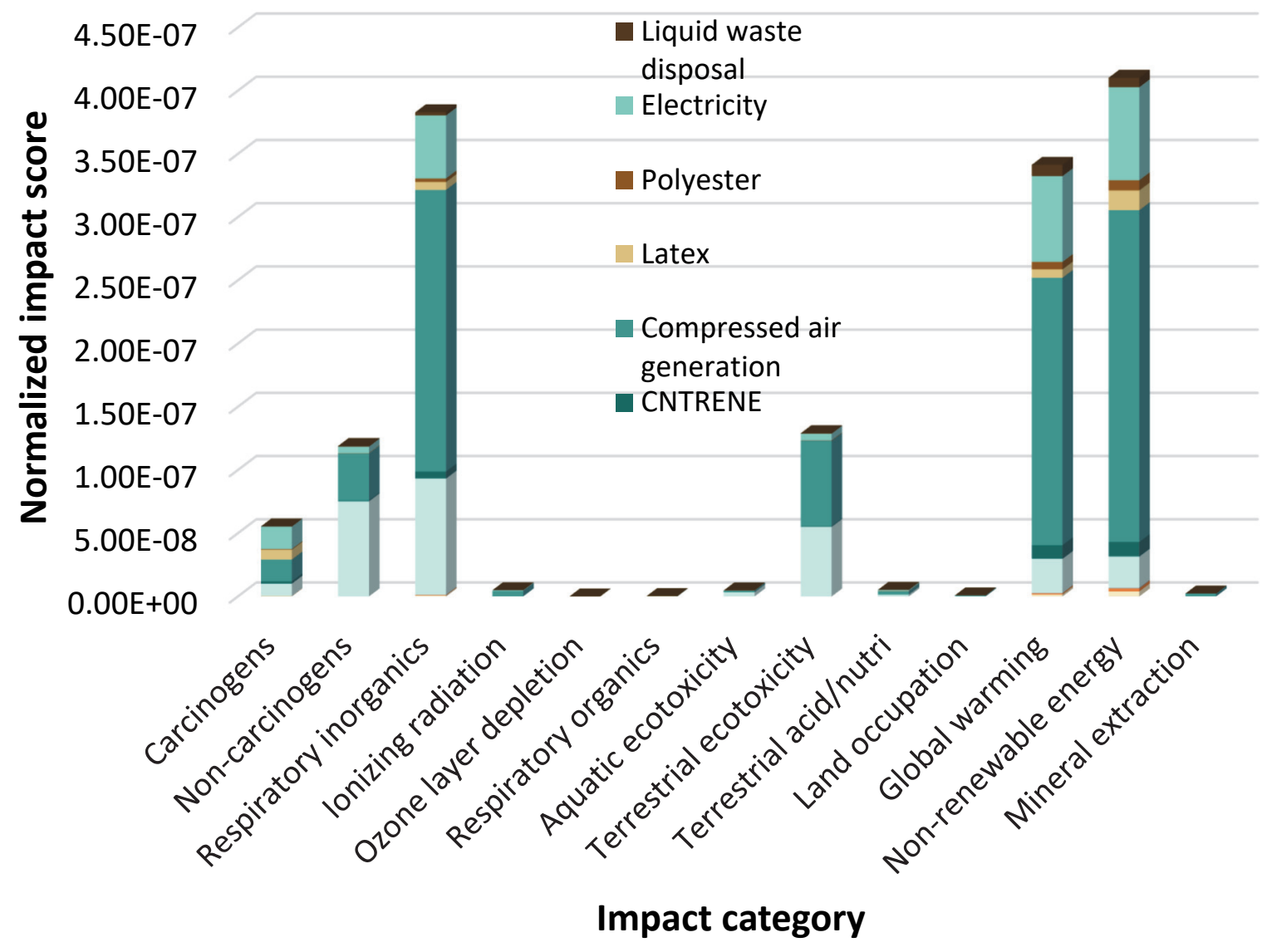


Figure 22. Normalized impact scores for the moisture sensor, version 3 , using IMPACT 2002+ model.

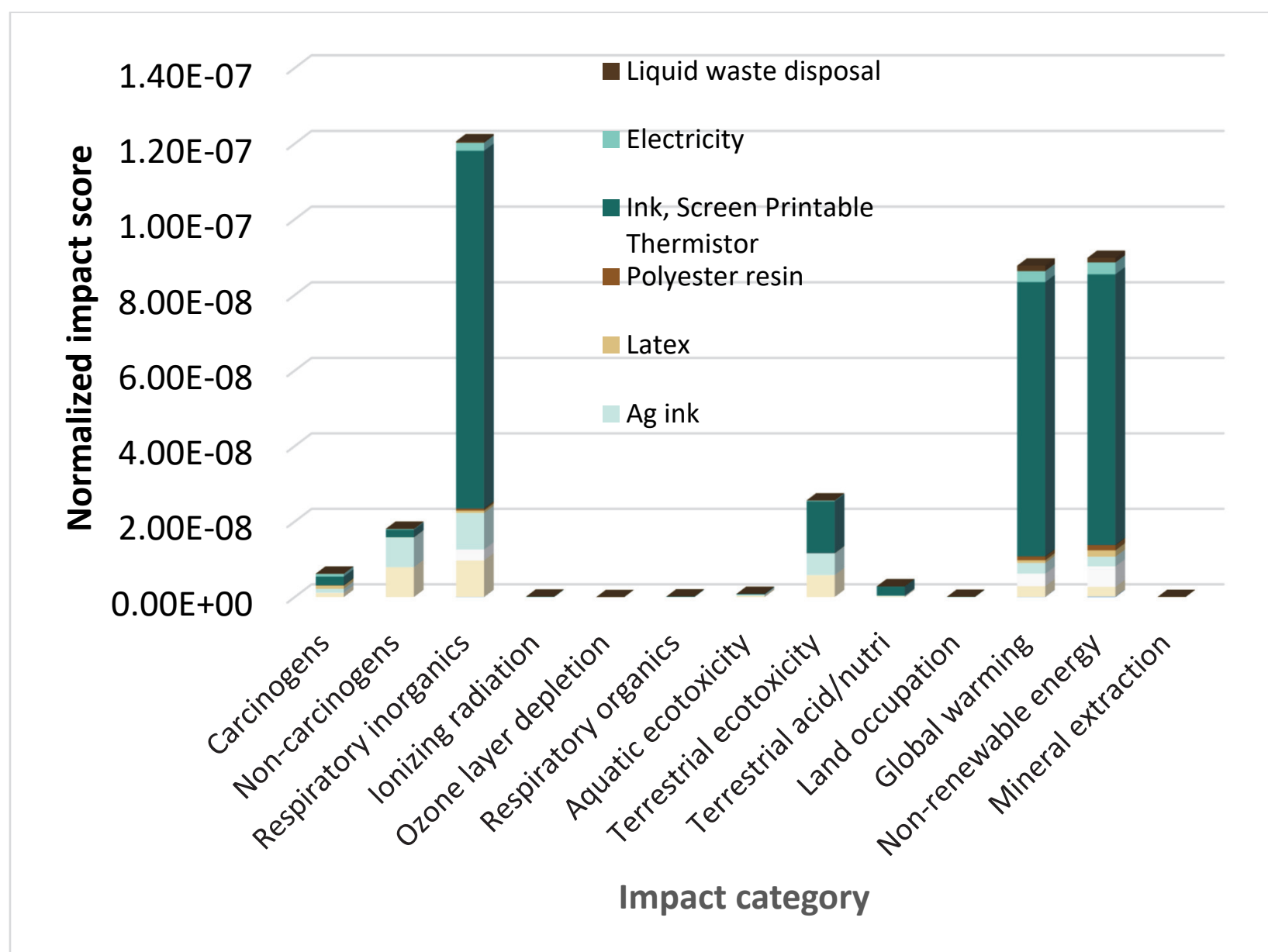




\section{Discussion and Conclusions}

In this report, we used ELCA as a diagnostic tool to inform Brewer Science regarding the particular processes promoting the greatest marginal environmental impacts in the development of their CNTRENE 1030 material and sensor products. ELCA allowed Brewer Science to track changes in their products' environmental impact as they optimized their devices for full production. Figure 23 summarizes the change in the normalized total environmental impact score during this optimization process (impacts calculated using the Eco-Indicator 99 and ReCiPe LCIA methods, summarized in Figure 24, gave complementary results). Overall, the environmental impacts of the flex and temperature sensors were greatly reduced by approximately 3-4 orders of magnitude, while the moisture sensor experienced a reduction of approximately one order of magnitude in its impact score. Most of these reductions resulted from reducing the water used in the manufacturing process (which would have to be later incinerated as hazardous waste due to the presence of CNTs) as well as optimizing the quantities of chemicals and raw materials included during manufacturing. Indeed, Brewer Science successfully reduced the environmental impact of its manufacturing processes for the flex and temperature sensors to the full extent of their control-where any further reductions would require fundamentally altering the shipping options for receiving raw materials. As an added benefit, the ELCA resulted in a significant cost savings in the manufacturing of the sensors. 
Figure 23. Change in the normalized total impact score with optimization of the temperature, moisture, and flex sensor manufacturing processes.

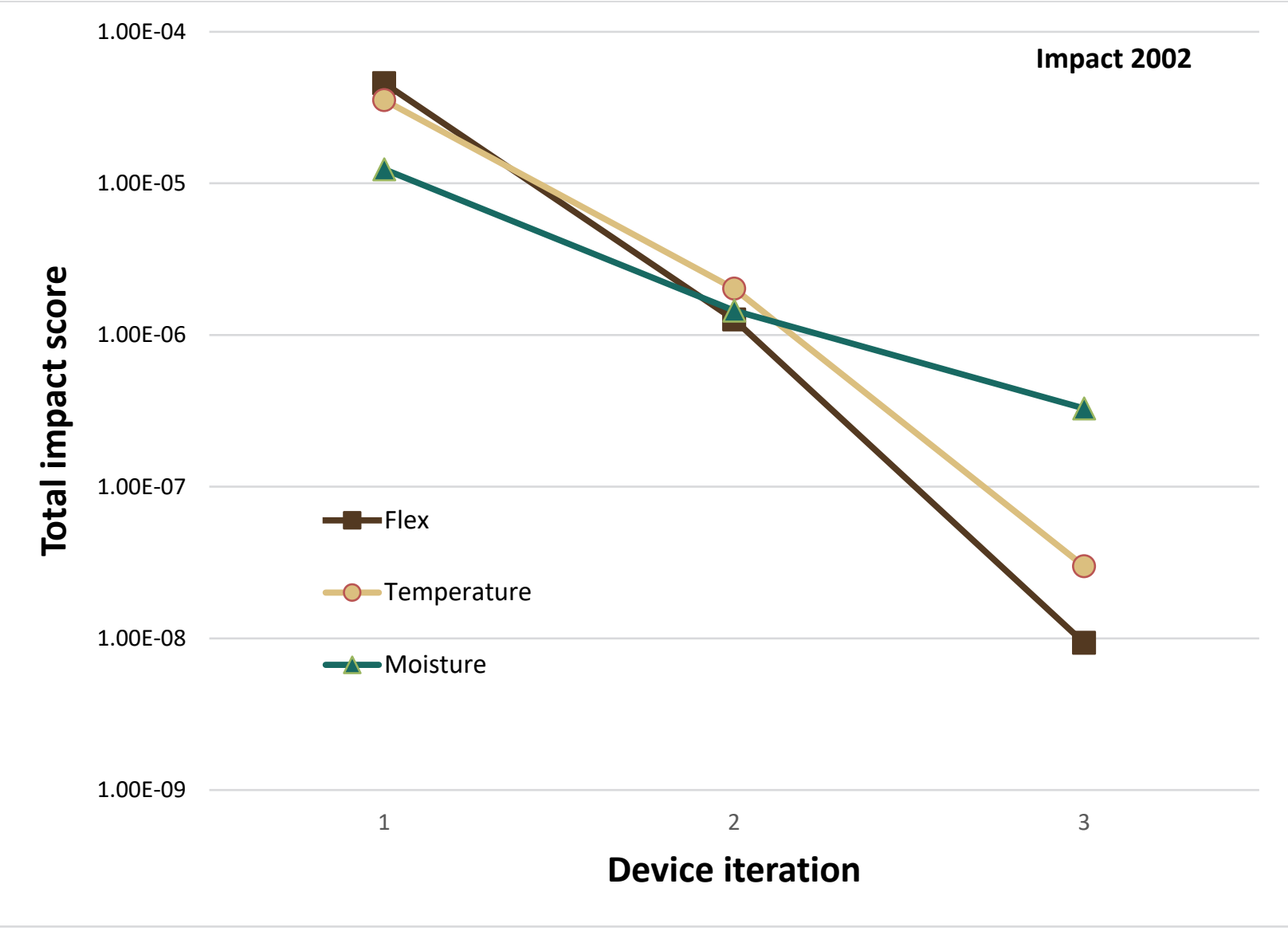


Figure 24. Change in the normalized total impact score with optimization of the temperature, moisture, and flex sensor manufacturing processes using (top) Eco-indicator 99 and (bottom) ReCiPe.
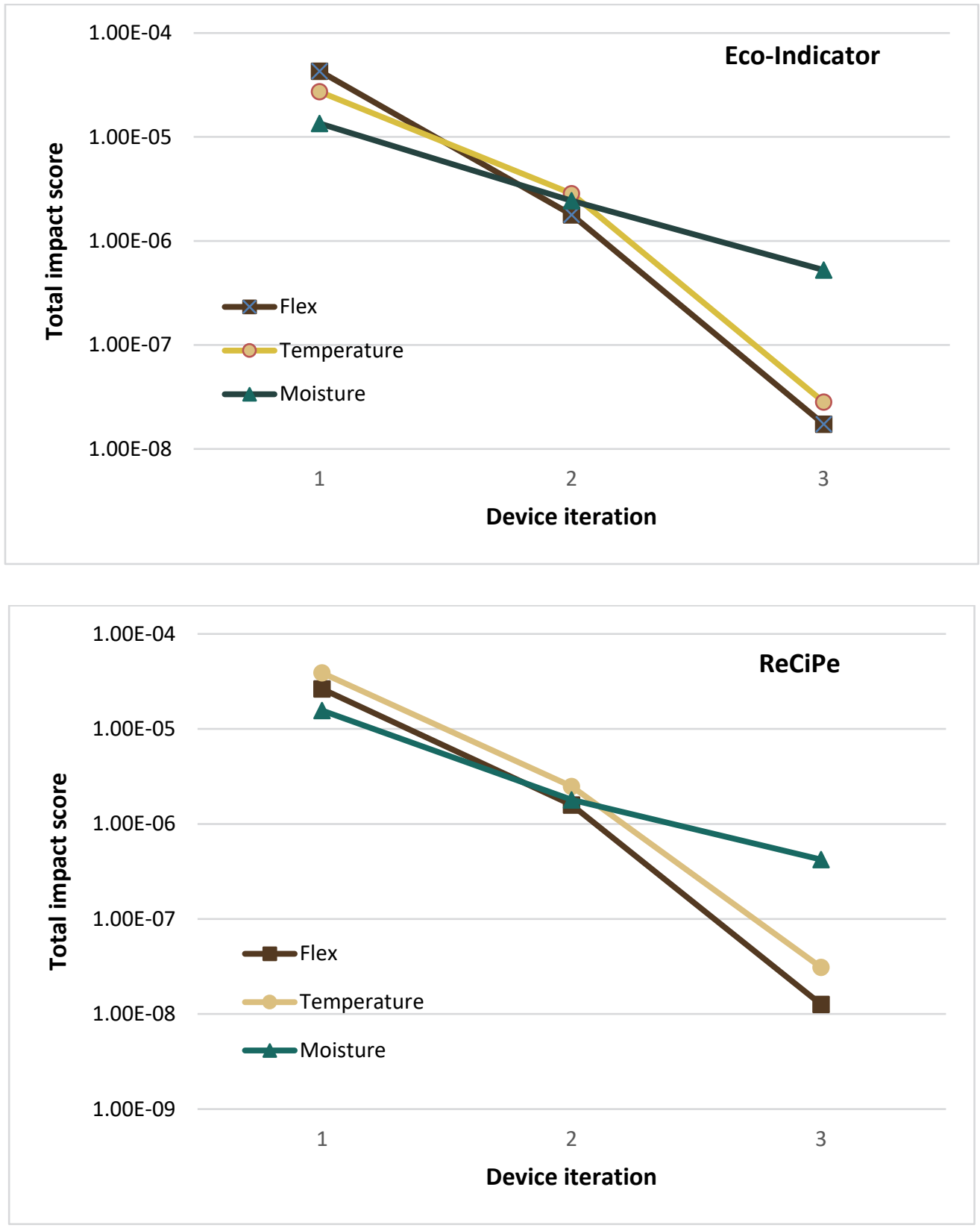


\section{References}

Chappell, M., Shih, W., Bledsoe, J. K., Cox, C., Janzen, D., Gibbons, S., Patel, R., Kennedy, A., Brame, J., Brondum, M., Diamond, S., Coleman, J., Edwards, D., and Steevens, J. A. 2017. Environmental Life Cycle Assessment for a Carbon Nanotube-Based Printed Electronic Sensor Platform. In "TechConnect 2017," Washington, DC.

Eckelman, M. J., Mauter, M. S., Isaacs, J. A., and Elimelech, M. 2012. New Perspectives on Nanomaterial Aquatic Ecotoxicity: Production Impacts Exceed Direct Exposure Impacts for Carbon Nanotoubes. Environmental Science \& Technology 46, 2902-2910.

Finnveden, G., Hauschild, M. Z., Ekvall, T., Guinée, J., Heijungs, R., Hellweg, S., Koehler, A., Pennington, D., and Suh, S. 2009. Recent developments in Life Cycle Assessment. Journal of Environmental Management 91, 1-21.

Frischknecht, R., Jungbluth, N., Althaus, H.-J., Doka, G., Dones, R., Heck, T., Hellweg, S., Hischier, R., Nemecek, T., Rebitzer, G., and Spielmann, M. 2005. The ecoinvent database: Overview and methodological framework. Intl. J. Life Cycle Assess. 10, 3-9.

Goedkoop, M., Heijungs, R., Huijbregts, M. A. J., Schryver, A. D., Struijs, J., and van Zelm, R. 2009. "ReCiPe 2008: A life cycle impact assessment method which comprises harmonised category indicators at the midpoint and the endpoint level." Ministry of Housing, Spatial Planning and Environment, Netherlands.

Goedkoop, M., and Spriensma, R. 2001. "Eco-indicator 99 Methodology report."

Huntzinger, D. N., and Eatmon, T. D. 2009. A life-cycle assessment of Portland cement manufacturing: comparing the traditional process with alternative technologies. Journal of Cleaner Production 17, 668-675.

International Organization for Standarization. 2006a. ISO 14040 - Environmental management - Life cycle assessment - Principles and framework. pp. 20.

International Organization for Standarization. 2006b. ISO 14044 - Environmental management - Life cycle assessment - Principles and framework. pp. 46.

Jolliet, O., Margni, M., Charles, R., Humbert, S., Payet, J., Rebitzer, G., and Rosenbaum, R. 2003. IMPACT 2002+: A new life cycle impact assessment methodology. The International Journal of Life Cycle Assessment 8, 324.

Klöpffer, W. 1997. Life cycle assessment. Environmental Science and Pollution Research 4, 223-228.

McManus, M. C., and Taylor, C. M. 2015. The changing nature of life cycle assessment. Biomass and Bioenergy 82, 13-26.

Miettinen, P., and Hämäläinen, R. P. 1997. How to benefit from decision analysis in environmental life cycle assessment (LCA). European Journal of Operational Research 102, 279-294. 
Pennington, D. W., Potting, J., Finnveden, G., Lindeijer, E., Jolliet, O., Rydberg, T., and Rebitzer, G. 2004. Life cycle assessment Part 2: Current impact assessment practice. Environment International 30, 721-739.

Pré Consultants. 2010a. "Eco-Indicator 99 (H) V2.08," Netherlands.

Pré Consultants. 2010b. "Impact 2002+ V2.10," Netherlands.

Pré Consultants. 2011. "ReCiPe Endpoint (H) V1.06," Netherlands.

Rebitzer, G., Ekvall, T., Frischknecht, R., Hunkeler, D., Norris, G., Rydberg, T., Schmidt, W. P., Suh, S., Weidema, B. P., and Pennington, D. W. 2004. Life cycle assessment: Part 1: Framework, goal and scope definition, inventory analysis, and applications. Environment International 30, 701-720.

Stavropoulos, P., Giannoulis, C., Papacharalampopoulos, A., Foteinopoulos, P., and Chryssolouris, G. 2016. Life Cycle Analysis: Comparison between Different Methods and Optimization Challenges. Procedia CIRP 41, 626-631. 


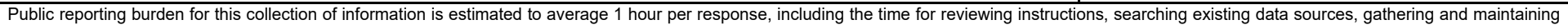

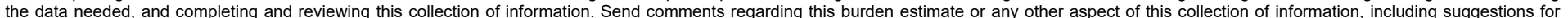

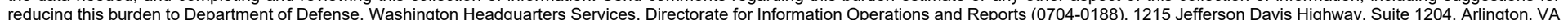

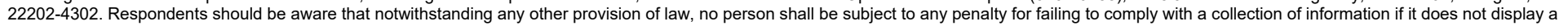
currently valid OMB control number. PLEASE DO NOT RETURN YOUR FORM TO THE ABOVE ADDRESS.

\begin{tabular}{l|l}
$\begin{array}{l}\text { 1. REPORT DATE (DD-MM-YYYY) } \\
\text { September } 2021\end{array}$ & $\begin{array}{l}\text { 2. REPORT TYPE } \\
\text { Final Technical Report }\end{array}$ \\
\hline
\end{tabular}

\section{TITLE AND SUBTITLE}

Environmental Life Cycle Assessment on CNTRENE® 1030 Material and CNT Based Sensors

3. DATES COVERED (From - To)

5a. CONTRACT NUMBER

5b. GRANT NUMBER

5c. PROGRAM ELEMENT NUMBER 633728

5d. PROJECT NUMBER 479448

Mark Chappell, Wu-Sheng Shih, Cynthia Price, Rishi Patel, Daniel Janzen, John Bledsoe, Kay Mangelson, Lesley Miller, Brooke Stevens, Joshua LeMonte, Joseph Demster, Vijaya Kayastha, Christopher Landorf, Stephen Gibbons, and Chris Cox

5e. TASK NUMBER A1090

5f. WORK UNIT NUMBER

8. PERFORMING ORGANIZATION REPORT NUMBER

ERDC/EL TR-21-12

See next page.

\section{DISTRIBUTION / AVAILABILITY STATEMENT}

Approved for public release; distribution is unlimited.

\section{SUPPLEMENTARY NOTES}

\section{ABSTRACT}

This report details a study investigating the environmental impacts associated with the development and manufacturing of carbon nanotube (CNT)-based ink (called CNTRENE 1030 material) and novel CNT temperature, flex, and moisture sensors. Undertaken by a private-public partnership involving Brewer Science (Rolla, Missouri), Jordan Valley Innovation Center of Missouri State University (Springfield, Missouri), and the US Army Engineer Research and Development Center (Vicksburg, Mississippi), this work demonstrates the environmental life cycle assessment (ELCA) methodology as a diagnostic tool to pinpoint the particular processes and materials posing the greatest environmental impact associated with the manufacture of the CNTRENE material and CNT-based sensor devices. Additionally, ELCA tracked the degree to which optimizing the device manufacturing process for full production also changed its predicted marginal environmental impacts.

\section{SUBJECT TERMS}

Environmental monitoring-Detectors; Detectors--Manufacturing processes; Nanostructured materials; Carbon nanotubes; Product life cycle--Environmental aspects

\section{SECURITY CLASSIFICATION OF:}

\section{a. REPORT}

Unclassified

\section{b. ABSTRACT}

Unclassified

\section{c. THIS PAGE}

Unclassified
17. LIMITATION OF ABSTRACT

18. NUMBER OF PAGES

46 19a. NAME OF RESPONSIBLE PERSON

19b. TELEPHONE NUMBER (include area code) 
US Army Engineer Research and Development Center

Environmental Laboratory

3909 Halls Ferry Road

Vicksburg, MS 39180

Brewer Science

2401 Brewer Drive

Rolla, MO USA 65401

Jordan Valley Innovation Center, Missouri State University

$524 \mathrm{~N}$ Boonville Ave

Springfield, MO 65806 